NBER WORKING PAPER SERIES

\title{
COUNTRY HETEROGENEITY AND THE INTERNATIONAL EVIDENCE ON THE EFFECTS OF FISCAL POLICY
}

\author{
Carlo Favero \\ Francesco Giavazzi \\ Jacopo Perego \\ Working Paper 17272 \\ http://www.nber.org/papers/w17272
}

\author{
NATIONAL BUREAU OF ECONOMIC RESEARCH \\ 1050 Massachusetts Avenue \\ Cambridge, MA 02138 \\ August 2011
}

Paper prepared for the Fiscal Policy, Stabilization and Sustainability Conference, Florence 6-7 June 2011. We thank Alberto Alesina, Morten Ravn, Luigi Spaventa, participants in the conference, and in the conference in honour of M.Hashem Pesaran, Cambridge, June 2011, for many helpful comments and suggestions. This paper is produced as part of the project Growth and Sustainability Policies for Europe (GRASP), a Collaborative Project funded by the European Commission's Seventh Research Framework Program, contract number 244725. The views expressed herein are those of the authors and do not necessarily reflect the views of the National Bureau of Economic Research.

NBER working papers are circulated for discussion and comment purposes. They have not been peerreviewed or been subject to the review by the NBER Board of Directors that accompanies official NBER publications.

(C) 2011 by Carlo Favero, Francesco Giavazzi, and Jacopo Perego. All rights reserved. Short sections of text, not to exceed two paragraphs, may be quoted without explicit permission provided that full credit, including $\odot$ notice, is given to the source. 
Country Heterogeneity and the International Evidence on the Effects of Fiscal Policy

Carlo Favero, Francesco Giavazzi, and Jacopo Perego

NBER Working Paper No. 17272

August 2011

JEL No. E62,H60

\begin{abstract}
This paper shows how the richer frequency and variety of fiscal policy shocks available in an international sample can be analyzed recognizing the heterogeneity that exists across different countries. The main conclusion of our empirical analysis is that the question "what is the fiscal policy multiplier" is an ill-posed one. There is no unconditional fiscal policy multiplier. The effect of fiscal policy on output is different depending on the different debt dynamics, the different degree of openness and the different fiscal reaction functions across different countries. There are many fiscal multipliers and an average fiscal multiplier is of very little use to describe the effect of exogenous shifts in fiscal policy on output.

Carlo Favero

Department of Finance

Bocconi University and IGIER

Via Röntgen, 1

20136 Milano, ITALY

carlo.favero@uni-bocconi.it

Francesco Giavazzi

Department of Economics

MIT, E52-383-A

Cambridge, MA 02139

and NBER

francesco.giavazzi@unibocconi.it

Jacopo Perego

IGIER Universita' Bocconi

1 via Roentgen

20136 Milano

Italy

jacopo.perego@unibocconi.it
\end{abstract}




\title{
Country Heterogeneity and the International Evidence on the Effects of Fiscal Policy
}

\author{
Carlo Favero* Francesco Giavazzi ${ }^{\dagger}$ Jacopo Perego ${ }^{\ddagger}$
}

July 26, 2011

\begin{abstract}
This paper shows how the richer frequency and variety of fiscal policy shocks available in an international sample can be analyzed recognizing the heterogeneity that exists across different countries. The main conclusion of our empirical analysis is that the question "what is the fiscal policy multiplier" is an ill-posed one. There is no unconditional fiscal policy multiplier. The effect of fiscal policy on output is different depending on the different debt dynamics, the different degree of openness and the different fiscal reaction functions across different countries. There are many fiscal multipliers and an average fiscal multiplier is of very little use to describe the effect of exogenous shifts in fiscal policy on output.
\end{abstract}

Keywords: Fiscal policy, Public debt, Government budget constraint, Global VAR models.

JEL Classification: H60, E62

\section{Introduction}

Measuring the effect of fiscal policy requires collecting a sample of episodes of exogenous shifts in fiscal stance. Such episodes, however, are rather rare at the level of an individual country. This is why, in order to obtain more precise estimates, it is tempting to pool fiscal shocks from different countries and to study their effects in the context of an international panel. Different countries, however, are different: in order to estimate fiscal multipliers

${ }^{*}$ Deutsche Bank Chair in Asset Pricing and Quantitative Finance, Università Bocconi, IGIER and CEPR. Via Roentgen 1, Milan 20136, Italy, carlo.favero@unibocconi.it.

${ }^{\dagger}$ Università Bocconi, Massachusetts Institute of Technology, IGIER, CEPR and NBER. Via Roentgen 1, Milan 20136, Italy, francesco.giavazzi@unibocconi.it.

${ }^{\ddagger}$ Università Bocconi, IGIER. Via Roentgen 1, Milan 20136, Italy, jacopo.perego@unibocconi.it.

Paper prepared for the Fiscal Policy, Stabilization and Sustainability Conference, Florence 6-7 June 2011. We thank Alberto Alesina, Morten Ravn, Luigi Spaventa, participants in the conference, and in the conference in honour of M.Hashem Pesaran, Cambridge, June 2011, for many helpful comments and suggestions. This paper is produced as part of the project Growth and Sustainability Policies for Europe (GRASP), a Collaborative Project funded by the European Commission's Seventh Research Framework Program, contract number 244725 . 
using an international panel one must recognize that countries are heterogeneous. This paper considers three sources of heterogeneity: two in the transmission of fiscal shocks and one in how fiscal shocks themselves are generated. The first is specific to the analysis of fiscal policy: countries are heterogeneous in their fiscal reaction functions and therefore in their debt dynamics. Following a fiscal shock different countries will aim at stabilizing the debt-to-GDP ratio at different levels and over different horizons. The second dimension of heterogeneity comes from different degrees of openness, which affect the way the economy responds to domestic and international shocks. The third is related to heterogeneity in the style of fiscal policy, that is in the contemporaneous correlation of shifts in taxes and spending. The aim of this paper is to show how the richer frequency and variety of fiscal policy shocks available in an international sample can be analyzed recognizing that these sources of heterogeneity exist across different countries.

The thin empirical literature which uses cross-country data to measure the effects of fiscal policy has so far overlooked heterogeneity. In Alesina and Ardagna (2010) and IMF (2010), for instance, fiscal multipliers are estimated by pooling all countries together, leaving the country fixed effect as the unique source of heterogeneity in the panel estimation. The papers by is Ilzetzki (2010) and Ilzetzki and Végh (2011) allow for the response to fiscal shocks to be heterogeneous across different groups of countries. However, they do not allow for interdependence, that is for the propagation of fiscal shocks across countries, nor for heterogeneity in debt levels. ${ }^{1}$

Recognizing that different countries start from different debt levels is important because fiscal reactions functions might differ depending on the level of debt and on the speed at which it accumulates or declines. The importance of keeping track of the debt dynamics in the analysis of fiscal policy has been pointed out by Favero and Giavazzi (2007), Corsetti, Meier and Mueller (2009), Leeper (2010) and Zubairy (2011). These papers show that studying the effects of shifts in fiscal policy without tracking the debt dynamics induced by such shifts might lead to fiscal multipliers computed along unsustainable fiscal paths, that is, along a path for the debt that is at odds with the beliefs of those who hold government bonds. In other words, correctly estimated fiscal multipliers should not overlook the fact that the government's fiscal actions are subject to an intertemporal budget constraint. Consider, for example, a positive shift in government spending. Following the shift, the government may respect its budget constraint by adjusting taxes and spending so as to keep the ratio of public debt-to-GDP stable, or it may delay the adjustment and in the meantime let the debt ratio grow. It may even plan to use the inflation tax. The choice of the policy maker will depend on its preferences, its policy targets and the initial debt level: different choices will induce different responses of output and other macro variables to the same fiscal shocks. Analyses of fiscal policy that do not allow for this source of heterogeneity will produce an "aggregate" fiscal multiplier that could be totally irrelevant for the policy makers. As Leeper (2010) correctly argues, "Fiscal policy will shed its alchemy

\footnotetext{
${ }^{1}$ Also, in both papers fiscal shocks are identified within a VAR, an identification strategy which runs against the problem of "non-invertibility" in the presence of fiscal foresight, i.e. whenever shifts in fiscal policy are anticipated.
} 
label when the question "What is the fiscal multiplier?" is no longer asked, and detailed analyses of unsustainable fiscal policies are no longer conducted".

This paper studies fiscal multipliers estimating a multi-country Global non-linear model obtained by augmenting a global VAR (GVAR) ${ }^{2}$ with each country's (non linear) debt-deficit dynamics. The model thus allows for international spillovers and for the possibility that such spillovers, as mentioned above, work differently in different countries. We study the transmission mechanism of a particular set of shifts in fiscal policy, those identified via the "narrative" method in Devries et al. (2011). These are, so far, the only available set of narrative multi-country shocks. As it is well known, the advantage of the narrative identification method is that it avoids the inversion of the MA representation of a VAR, needed to identify structural shocks. The narrative identification is therefore robust to the effects of fiscal foresight, i.e. to the possibility that shifts in fiscal policy are anticipated (see Hansen and Sargent 1991, Leeper et al 2008, Ramey 2011). Our main point, however - namely, the importance of allowing for heterogeneity — is independent of the particular identification strategy: it applies identically to the analysis of fiscal shocks identified imposing enough constraints on a structural VAR.

The analysis of narrative fiscal shocks across different countries reveals another source of heterogeneity: tax and spending shocks are typically not independent of one another and the style of fiscal corrections differs across countries. This simple fact is confirmed by the set of fiscal consolidation shocks identified in Devries et al. (2011) and reproduced in Figure 1. In this sample, which spans from 1978 to 2009, the contemporaneous correlation of shocks to taxes and government spending is in general different from zero and the relative contribution of revenues and expenditures to the overall shift in fiscal stance differs significantly across countries. Ramey (2011) recognizes this point when she observes that the correlation between revenue and spending shocks may change also within a country. When analyzing the spending shock corresponding to the Korean war she points out that what makes that shock different from WWII shocks is that it was accompanied by a contemporaneous increase in taxes, something that did not happen during WWII. This paper explicitly recognizes that shocks to revenues and expenditures are correlated and allows for such correlation to differ across countries. As we shall see, this additional source of heterogeneity has important implications for the analysis of the transmission of fiscal policy shocks.

Once we allow for all three sources of heterogeneity - in fiscal reaction functions, in openness and in the style of fiscal corrections - and we compute multipliers along paths that are not inconsistent with a positive value of government bonds, we find results that sharpen our understanding of the effects of fiscal policy. In particular: (i) international spillovers are important. In the case of Canada, for instance, it makes a big difference whether a fiscal consolidations happens contemporaneously also in the U.S., or only in Canada; (ii) the initial level of debt and the stability of the debt ratio seem to determine whether a shift in fiscal policy has "keynesian" or "non-keynesian" effects. In our group of

\footnotetext{
${ }^{2}$ See, for example, Pesaran, Schuermann, Weiner (2004) and Dees, di Mauro, Pesaran, Smith (2007).
} 
countries we find evidence of non-keynesian effects only in Japan. This is the only country in our sample where fiscal policy does not respond to the level of debt and where the debt level is non mean-reverting.

Beyond contributing to the empirical literature on the macroeconomic effects of fiscal policy our results could be used to discriminate between alternative theoretical models. For instance, as suggested by Perotti (2011), the finding of a fiscal multiplier smaller or larger than one can discriminate between a neoclassical and a new-Keynesian model. In neoclassical models with lump-sum taxation where government spending is pure waste and produces no externality, a shift in expenditures affects the economy via a pure wealth effect. As spending rises, the need to satisfy the government intertemporal budget constraint makes the present value of taxes rise correspondingly. Note that this channel is overlooked in models that estimate fiscal multipliers omitting the government's intertemporal constraint. Forward-looking agents see their after-tax labour income reduced and will therefore cut down their consumption of both goods and leisure. Consumption falls and GDP increases (depending on the elasticity of labor supply) less than the increase in government spending. The output multiplier is less than 1. In contrast, in a Keynesian model in response to a rise in government spending consumption increases and the output multiplier is typically larger than 1 , provided that monetary policy does not put too much weight on output, so that the expansion in output and labor demand are sufficient to generate an increase in the real wage.

The paper is organized as follows. In Section 2 we describe a model that allows for heterogeneity in fiscal multipliers. In Section 3 we provide some evidence on the heterogeneity in the style of fiscal corrections. Section 4 shows how we allow for heterogeneity and how we keep track of debt dynamics in the analysis of fiscal multipliers. Section 5 presents our empirical results and discusses what difference all of this makes. Section 6 examines the robustness of our results to the potential endogeneity of narrative shocks. Section 7 concludes.

\section{Measuring International Fiscal Multipliers}

As mentioned in the introduction, this paper does not address the issue of the identification of fiscal policy shocks. We instead focus our attention on the transmission mechanism of fiscal shocks using the shocks identified in Devries et al. (2011), who apply the narrative method originally proposed by Romer and Romer (2010, hereafter R\&R) to identify shifts in fiscal policy in a group of 15 OECD countries.

The typical approach in this literature (e.g. Alesina Ardagna 2010, IMF 2010) is to study the fiscal transmission mechanism via a panel estimation of a cross-country output equations. The growth rate of real GDP is regressed on a set of current and lagged values of fiscal shocks (tax hikes and expenditure cuts) and lagged GDP growth. In particular, IMF (2010) estimates, on the sample of fifteen OECD countries ${ }^{3}$ the following specification:

\footnotetext{
${ }^{3}$ Australia, Belgium, Canada, Denmark, Finland, France, Germany, Ireland, Italy, Japan, Portugal,
} 


$$
\Delta y_{i, t}=\alpha+A_{1}(L, 1) \Delta y_{i, t-1}+B(L, 2) \varepsilon_{i, t}^{g}+C(L, 2) \varepsilon_{i, t}^{\tau}+\lambda_{i}+\nu_{t}+\mu_{i, t}
$$

The equation includes a full set of country dummies, $\lambda_{i}$, to account for differences in trend growth rates across countries and time dummies, $\nu_{t}$, to account for global shocks, such as shifts in oil prices or the global business cycle. The simulation of the dynamic effects of the structural shocks generates a single fiscal multiplier restricted to be the same for all countries.

Differently from this approach, we study the effects of fiscal shocks in our panel of countries embedding heterogeneity in the style of fiscal corrections, in openness and in the debt-deficit dynamics in an open-economy model. The model is specified to contain the minimal set of macroeconomic variables necessary to pin down the debt-deficit dynamics endogenously:

$$
\begin{array}{ll}
\tilde{X}_{i, t}=C_{i, 1}+C_{2} \tilde{X}_{i, t-1}+\varphi_{i} B_{i, t-1}+\varphi_{i, 1} Z_{i, t}+\varphi_{i, 2} Z_{i, t-1}+\gamma_{i}^{g} \varepsilon_{i, t}^{g}+\gamma_{i}^{\tau} \varepsilon_{i, t}^{\tau}+\mu_{i, t} & \text { if } i \neq U S \\
X_{i, t}=C_{i, 1}+C_{i, 2} X_{i, t-1}+\varphi_{i} B_{i, t-1}+\gamma_{i}^{g} \varepsilon_{i, t}^{g}+\gamma_{i}^{\tau} \varepsilon_{i, t}^{\tau}+\mu_{i, t} & \text { if } i=U S
\end{array}
$$

with

$$
\begin{aligned}
\tilde{X}_{i, t} & \equiv\left[y_{i, t}, g_{i, t}, \tau_{i, t}, i_{i, t}, p_{i, t}, s_{i, t}\right] \\
X_{i, t} & \equiv\left[y_{i, t}, g_{i, t}, \tau_{i, t}, i_{i, t}, p_{i, t}\right] \\
Z_{i, t} & \equiv\left[y_{i, t}^{\star}, s_{i, t}^{\star}\right] \\
\boldsymbol{\varphi}_{i} & \equiv\left[\varphi_{i, 1}, \varphi_{i, 2}, \varphi_{i, 3}\right]
\end{aligned}
$$

augmented by the following set of identities:

$$
\begin{aligned}
Y_{i, t} & =e^{y_{i, t}+p_{i, t}} \\
g r_{i, t} & =\left(Y_{i, t}-Y_{i, t-1}\right) / Y_{i, t-1} \\
\tilde{B}_{i, t} & =Y_{i, t} B_{i, t} \\
r_{i, t} & =e^{i_{i, t}+p_{i, t}} / \tilde{B}_{i, t-1} \\
B_{i, t} & =B_{i, t-1}\left(\frac{1+r_{i, t}}{1+g r_{i, t}}\right)+\frac{e^{g_{i, t}-e^{\tau_{i, t}}}}{e^{y_{i, t}}}+\zeta_{i, t} \\
y_{i, t}^{\star} & =\sum_{j=1}^{N-1} w_{i j} y_{j, t} \quad i \neq j \\
s_{i, t}^{\star} & =\sum_{j=1}^{N-1} w_{i j} s_{j, t} \quad i \neq j
\end{aligned}
$$

This specification requires a few comments:

- the model allows for the correlation between revenue and spending shocks and for heterogeneity across countries in the conduct of fiscal policy. When a fiscal adjustment of $1 \%$ of the GDP is simulated in country $i$, a shock of size $\frac{1}{1+\beta}$ to $\varepsilon_{i, t}^{g}$ is paired with a shock of size $\frac{\beta}{1+\beta}$ to $\varepsilon_{i, t}^{\tau}$, where $\beta$ is computed using the fact that

Spain, Sweden, the United Kingdom, and the United States. 


$$
E_{t}\left(\varepsilon_{i, t}^{\tau} \mid \varepsilon_{i, t}^{g}\right)=\beta \varepsilon_{i, t}^{g}
$$

- the model includes a non linear debt feedback ${ }^{4}$. Therefore, the impact of fiscal shocks on output depends on the initial conditions at which such shocks occur ${ }^{5}$. Following a fiscal shock, however, debt stabilization is not imposed: the coefficients on the debt feedback are freely estimated. Note that the coefficients $\boldsymbol{\varphi}_{i, 1}$ are allowed to be heterogeneous across countries, so that our specification can accommodate heterogeneous debt-deficit dynamics. One restriction we impose on the $\boldsymbol{\varphi}_{i, 1}$ coefficients is that, for every country, debt only appears in the equations for $g_{i, t}, \tau_{i, t}, i_{i, t}$ and $p_{i, t}$ ${ }^{6}$;

- the model allows to compute impulse responses to fiscal shocks keeping track of the debt dynamics. If $\varepsilon_{i, t}^{g}$ and $\varepsilon_{i, t}^{\tau}$ are validly identified shocks, the only additional assumption required to track the debt dynamics by appending (9) to the VAR, is that $\zeta_{i, t}$ is strongly exogenous. $\zeta_{i, t}$, captures the statistical discrepancies in the OECD accounts of the debt-deficit dynamics, and is the only additional shock that needs to be added to the VAR in order to compute the debt dynamics;

- $\varepsilon_{i, t}^{g}$ and $\varepsilon_{i, t}^{\tau}$ are identified (in Devries et al. 2011) with the narrative method, thus not requiring the inversion of the Moving Average representation of a VAR. Shocks identified from the narrative method are directly included in the VAR and impulse responses with respect to these shocks can be directly derived from the joint simulation of (2) and the above identities;

- the degree of openness is allowed to differ across countries by letting the coefficients in $\varphi_{i, 2}$ and $\varphi_{i, 3}$ to be country-specific;

- the U.S. is treated as a closed economy. This is not an identifying restriction. We have imposed that foreign variables have no impact on the U.S. economy to be able to compare our results with the existing empirical evidence that typically analyzes the effect on fiscal policy in the U. S. within the context of a closed economy specification. When the validity of the closed economy restrictions for the U.S. is tested statistically, the hypothesis that all the relevant coefficients are zero could not be rejected.

This specification allows for all three sources of heterogeneity discussed in the introduction. In the following sections we shall consider each of them in detail before illustrating our empirical results.

\footnotetext{
${ }^{4}$ Ghosh et al.(2011) also find evidence of the importance of dbet feedback and non-linearities in an international panel of advaced economies

${ }^{5}$ Impulse responses and their associated confidence intervals are computed by the simulation technique described in Favero-Giavazzi(2007)

${ }^{6}$ Zubairy(2011) allows for a debt feedback in a DSGE model, while Killian and Vigfusson(2010), in the case of oil shocks, and Auerbach and Gorodnichenko (2011) also allow for the presence of asymmetries and non-linearities in VAR models
} 


\section{$3 \quad$ Heterogeneity in the style of fiscal corrections}

The international shifts in fiscal policy identified in IMF (2010) are tax increases and spending cuts implemented to reduce the budget deficit and to put the public finances on a sustainable path ${ }^{7}$. Such shocks are identified for a group of OECD countries using the record available in official documents to identify the size, timing, and principal motivation for the fiscal actions taken by each country. ${ }^{8}$ This identification strategy applies to a panel of countries the idea originally proposed in $R \& R$ who used presidential speeches, Congressional reports and other public records to identify all major U.S. postwar tax policy actions. However, the IMF's shocks differ from R\&R's in two important dimensions. $\mathrm{R} \& \mathrm{R}$ focus only on revenue shocks and identify two main types of legislated exogenous tax changes: those driven by long-run motives, such as to foster long-run growth, and those aiming to deal with an inherited budget deficit. IMF (2010) considers instead both expenditure and revenue shocks and focuses only on fiscal actions motivated by the objective of reducing the budget deficit. As a matter of fact, in the IMF sample, fiscal shocks only refer to fiscal consolidations episodes, there are no instances of deficit-driven fiscal expansions.

This observation raises a question on a potential truncation problem in the in Devries et al. (2011) shocks' series. A truncation would arise if there were some omitted deficitdriven fiscal expansion episodes. Although we cannot check for truncation in general, there are two countries in our sample for which this is possible, the US and the UK. Consider the case of the United States, for which the Devries et al. (2011) shocks can be compared with the $\mathrm{R} \& \mathrm{R}$ narrative shocks. The $\mathrm{R} \& \mathrm{R}$ narrative shocks show both positive and negative observations, however these shocks are constructed by aggregating tax shocks deficit-driven and tax shocks driven by the long-run growth motive. Deficit-driven fiscal expansions never occur in the $\mathrm{R} \& \mathrm{R}$ sample, where virtually all tax shocks driven by the long-run motive are expansionary (i.e. negative tax shocks) and all the deficit-driven tax shocks are contractionary (i.e. positive tax shocks). Therefore the $R \& R$ deficit-driven shocks, which are directly comparable to those identified by Devries et al. 2011, show no evidence of truncation. Moreover in the R\&R identification, deficit-driven tax shocks and long-run tax shocks are virtually orthogonal (their correlation is -0.08). The same observation namely the fact that the series of deficit-driven tax shocks is almost exclusively composed of tax increases - applies also to the narrative series of deficit-driven shocks identified by Cloyne (2011) for the UK. Note, however, that the fact that the multiplier computed using only deficit-driven fiscal shocks is unbiased doesn't make it directly comparable with the one computed using R\&R's series. The former is a multiplier with respect to deficit-driven fiscal shock only. The latter, instead, is relative to a generic fiscal shock, either long-run or deficit driven, obtained by imposing the restriction that the output responses to long-run motivated tax changes and to deficit-driven tax changes are identical.

The original IMF sample includes fifteen OECD countries. The data are annual and

\footnotetext{
${ }^{7}$ The dataset is available on the IMF's website (http://www.imf.org/external/pubs/cat/longres.aspx?sk=24892.0)

${ }^{8}$ See IMF World Economic Outlook, October 2010, p.96.
} 
extend from 1978 to 2009. In this sample, there are 173 episodes of fiscal consolidation identified. In what follows, however, we focus our attention on a representative subsample of eight countries: Belgium, Canada, France, Italy, Japan, United Kingdom, Sweden and the United States. This choice is constrained by the availability of the data needed to track the debt dynamics - such as general government gross debt and interest payments - which for some of the countries in the original IMF sample are available only for a too short time span. We label $\varepsilon_{i, t}^{g}$ the narrative measure of a shock to expenditures (measured as a percent of GDP) in country $i$ in year $t$, while $\varepsilon_{i, t}^{\tau}$ are the identified shocks to revenues.

\section{[Insert Figure 1 Here]}

As it is clear from Figure 1, revenue shocks and expenditure shocks are correlated, and the fiscal mix historically used to achieve a correction in the budget is heterogeneous across countries. In the case of the U.S., for example, the historical data tell us that a correction of the primary surplus of one per cent of GDP is typically achieved with a mix of $60 \%$ expenditure cuts and $40 \%$ revenue increases. In the case of Japan, instead, the same adjustment is obtained through a mix of $80 \%$ in expenditure cuts and $20 \%$ in revenues increases.

The evidence in Figure 1 has two important implications. First, it tells us that, for basically all the countries considered, the simulation of the effects of a shock to government spending, assuming no contemporaneous shift in taxes, would violate the historical pattern. Such an experiment would describe a situation that does not exist in the data because $\varepsilon_{i, t}^{\tau}$ shocks have never occurred independently of $\varepsilon_{i, t}^{g}$ shocks, at least in this sample. This observation casts strong doubts on the usefulness of using the narrative shocks identified in IMF (2010) to study the effects of tax-based adjustments separately from those of expenditure-based adjustments. If the identified spending and revenue shocks have a specific pattern of correlation, that specific pattern should be preserved when simulating the effect, for instance, of a tax shock. In other words, it would be difficult to interpret the effect of a tax shock which is assumed to take place independently of an expenditure shock since such an occurrence has never been observed in the sample from which the data are drawn. Second, the evidence described in Figure 1 implies that, when studying the international evidence of the effects of a fiscal correction, one should allow for this source of heterogeneity in policy, that is for the different styles of such corrections across countries. A shift in the primary surplus equivalent to one per cent of GDP is not achieved with the same mix in all countries. This restriction, which is implicitly imposed in IMF (2010), violates the heterogeneity present in the data.

To illustrate the importance of this point we have run an experiment focusing on the United States only. Consider a regression of output growth on a distributed lag of fiscal shocks estimated to evaluate the impact on output of i) a tax shock of one per cent of GDP simulated setting expenditure shocks to zero (the experiment run by $R \& R$ ), and ii) an adjustment of the primary surplus of one per cent of the GDP obtained using the 
historical mix of shifts in taxes and in expenditure. In practice, we have estimated the following two models, where $i=U S$ and $A(L, q)$ is a lag polynomial of degree $q^{9}$ :

$$
\begin{gathered}
\Delta y_{i, t}=\alpha+A(L, 1) \Delta y_{i, t-1}+B(L, 2) \varepsilon_{i, t}^{\tau}+\mu_{i, t} \\
\Delta y_{i, t}=\alpha+A_{1}(L, 1) \Delta y_{i, t-1}+B(L, 2) \varepsilon_{i, t}^{g}+C(L, 2) \varepsilon_{i, t}^{\tau}+\mu_{i, t}
\end{gathered}
$$

The results are reported in Figure 2. The multiplier obtained from (3), reported in the left-hand panel, is estimated by simulating a shock to $\varepsilon_{i, t}^{\tau}$ equivalent to $1 \%$ of GDP. On the other hand, the multiplier obtained from (4), reported in the right-hand panel, is estimated by simulating a shock of $\frac{1}{1+\hat{\beta}}$ to $\varepsilon_{i, t}^{g}$ and a shock of $\frac{\hat{\beta}}{1+\hat{\beta}}$ to $\varepsilon_{i, t}^{\tau}$. The coefficient $\hat{\beta}$ comes from the estimation of $\varepsilon_{i, t}^{\tau}=\alpha+\beta \varepsilon_{i, t}^{g}+\nu_{i, t}$ in the sample. In this second experiment the overall simulated shift in fiscal policy still amounts to $1 \%$ of GDP, but it now reflects the fiscal policy style observed in the data. As Figure 2 shows, the two multipliers are quite different.

The multiplier obtained using the actual fiscal correction style differs from zero only in the first year and is much smaller than that obtained by simulating an isolated tax shock which is negative and significant for three years.

\section{[Insert Figure 2 Here]}

In the light of this difference, we favour the idea of computing multipliers based on the historical correlation between shifts in taxes and in spending, rather than artificially setting to zero the correlation between the two. This is nothing new: the simulation of reduced form models such as a VAR not respecting the historical pattern of correlations present in the data would run against the Lucas (1976) critique.

\section{Heterogeneity in the transmission of fiscal shocks}

Countries are also heterogeneous in their fiscal reaction functions: following a fiscal shock, different countries will aim at stabilizing the debt-to GDP ratio at different levels and over different horizons. In other words, the effects of a shift in fiscal policy will depend on the country-specific debt-deficit dynamics: Figure 3 illustrates that this dynamics is clearly heterogeneous across the 8 countries in our sample.

\section{[Insert Figure 3 HeRe]}

Another dimension of heterogeneity is related to the different degrees of openness, because openness determines the size of the multiplier and the extent to which an economy is affected by international fluctuations. Openness varies a lot across the eight countries

\footnotetext{
${ }^{9}$ Where the lag-polynomial is defined as $M(L, q)=\sum_{i=0}^{q} \beta_{q} L^{q}$.
} 
in our sample. The U.S. is the closest of all. In most empirical investigations on the effect of fiscal policy it is treated as closed economy: we shall not depart from this hypothesis, assuming that the U.S. economy is unaffected by international fluctuations. This, however, is not true for smaller economies where the effect of a shift in fiscal policy, at home or abroad, will depend on the international economic environment in which such a shift takes place. For instance, differences in the response of the economy to a fiscal consolidation might depend on the international environment in which such a consolidation takes place. It has been argued, for example, that the sharply different response of the Irish economy to the two consolidations carried out during the 1980s - which resulted in a deep recession in 1981-82 and in an economic boom five years later - were associated with the very different economic conditions prevailing at the time in Ireland's main trading partner, the U.K.

The empirical model we adopt to measure the effects of a shift in fiscal policy addresses both sources of heterogeneity. It tracks, country by country, the debt-deficit dynamics, and it allows for different degrees of openness. In the remaining paragraphs of this section we discuss the two issues in turn.

\subsection{Tracking the path of the debt}

To track the country-specific debt dynamics we must first recognize that the equation which determines the evolution over time of the debt-income ratio is highly non-linear. The fact that this relation is non-linear is the reason why we believe it is important to track it by means of endogenous variables rather than simply augmenting the VAR with the government debt series. These endogenous variables are precisely those determining the path of government debt: the cost of debt service, the nominal growth rate and the primary deficit. In what follows, we derive the debt dynamics in terms of gross debt and, by doing that, we slightly depart from previous work such as Bohn (1998), which uses net government liabilities as his definition of public debt. We use gross debt for several reasons. First, statutory debt limits, when they exist, are usually imposed on gross debt. Second, gross debt is the measure which is more largely available to the public and, for this reason, it is more likely to be the one entering the information set of economic agents and hence influencing their decisions when responding to fiscal shocks. Third, there is an inherent difficulty in evaluating government assets, most of which do not have a market price to be used as a reference. The last reason is technical: in two of the countries in our sample, Sweden and the United Kingdom, the net debt series turns negative for some years. This is a problem because whenever the net debt comes close to zero in our simulation it induces an exploding path for the cost of debt service, hence making the system unstable and the simulation unfeasible.

In order to track the debt dynamics, we start from the two following identities:

$$
\begin{aligned}
\tilde{B}_{i, t}^{g} & \equiv \tilde{B}_{i, t}^{n}+\tilde{A}_{i, t} \\
\tilde{B}_{i, t}^{n} & \equiv \tilde{B}_{i, t-1}^{n}+\tilde{D}_{i, t}+\tilde{I}_{i, t}+\mu_{i, t} .
\end{aligned}
$$

where $\tilde{B}_{i, t}^{g}, \tilde{B}_{i, t}^{n}, \tilde{A}_{i, t}, \tilde{D}_{i, t}$ and $\tilde{I}_{i, t}$ denote, respectively, the nominal levels of gross debt, 
net debt, government assets, primary deficit and net interest payments. The error term, $\mu_{i, t}$, is to be interpreted as a zero-mean vector of statistical discrepancies. From (5), by adding and subtracting $\tilde{A}_{i, t-1}$ we get

$$
\tilde{B}_{t}^{g} \equiv \tilde{B}_{i, t-1}^{g}+\tilde{D}_{i, t}+\tilde{I}_{i, t}+\Delta \tilde{A}_{i, t}+\mu_{i, t}
$$

Dividing both sides of (6) by nominal GDP, $\tilde{Y}_{i, t}$, (and dropping the tilde to denote ratios to GDP) we have

$$
B_{i, t}^{g} \equiv \frac{\tilde{B}_{i, t-1}^{g}+\tilde{I}_{i, t}}{\tilde{Y}_{i, t}}+D_{i, t}+\nu_{i, t}+\mu_{i, t}
$$

$\nu_{i, t}=\Delta \tilde{A}_{t} / \tilde{Y}_{t}$ denotes the component in the change of gross public debt which is unrelated to the primary deficit or to interest payments and, instead, reflects asset sales or purchases. Since we have no economic model to determine the evolution of government assets, we shall assume that $\nu_{i, t}$ is an exogenous random variable. For notational convenience we define $\zeta_{i, t} \equiv \nu_{i, t}+\mu_{i, t}$ and from now on we drop the apex $g$ from $B_{i, t}^{g}$. Setting $r_{t}=\tilde{I}_{t} / \tilde{D}_{t-1}$ and $g r_{t}=D\left(\tilde{Y}_{t}\right) / \tilde{Y}_{t-1}$, from (7) we get

$$
B_{t}=B_{t-1}\left(\frac{1+r_{t}}{1+g r_{t}}\right)+D_{i, t}+\zeta_{i, t}
$$

This last equation shows that the dynamics of $B_{t}$ can be tracked using a parsimonious number of endogenous variables. Letting $y_{i, t}, g_{i, t}, \tau_{i, t}, i_{i, t}$ and $p_{i, t}$ be the logs of real output, real government expenditures and revenues, real net interest payments and the price deflator, respectively, we can track the dynamics described in (8) by use of the following set of identities:

$$
\begin{aligned}
Y_{i, t} & =e^{y_{i, t}+p_{i, t}} \\
g r_{i, t} & =\left(Y_{i, t}-Y_{i, t-1}\right) / Y_{i, t-1} \\
\tilde{B}_{i, t} & =Y_{i, t} B_{i, t} \\
r_{i, t} & =e^{i_{i, t}+p_{i, t}} / \tilde{D}_{i, t-1} \\
B_{i, t} & =B_{i, t-1}\left(\frac{1+r_{i, t}}{1+g r_{i, t}}\right)+\frac{e^{g_{i, t}-e^{\tau_{i, t}}}}{e^{y_{i, t}}}+\zeta_{i, t}
\end{aligned}
$$

Note that the fourth identity imposes a non-negativity constraint on the cost of financing the debt, a feature that will turn out to be very useful when simulating the model over periods of very low interest rates. Note also that, conditional on $X_{i, t} \equiv\left[y_{i, t}, g_{i, t}, \tau_{i, t}, i_{i, t}, p_{i, t}\right]$ and $\zeta_{i, t}$, system (9) is closed, which means that we have expressed the dynamics of gross debt, $B_{i, t}$ in terms of endogenous variables only.

In order to check how closely our debt-dynamics equation tracks the actual path of debt-GDP ratios of the eight countries in our sample, we have brought the system (9) to the data and simulated it forward starting in 1980, by feeding it with the actual values of $X_{i, t}$ and $\zeta_{i, t}$. Figure 3 reports the debt dynamics produced by this simulation, along with the actual ones. The two series are virtually not distinguishable. 


\subsection{Modelling heterogeneity in openness}

As mentioned above, we assume that our sample of countries consists of one closed economy, the U.S., and $n-1$ open economies. We parsimoniously model comovements in open economies by adopting the GVAR approach proposed by Schuerman et al (2004): a country-specific exogenous international variable, $y_{i, t}^{*}$, is constructed for each country through a weighted average of the foreign (log of) output, $y_{i, t}$

$$
y_{i, t}^{\star}=\sum_{j=1}^{n-1} w_{t}^{i j} y_{j, t} \quad i \neq j
$$

where the weights $w_{t}^{i j}$ are based on trade shares - the share of country $j$ in the total trade of country $i$ measured in U.S. dollars with $w_{t}^{i i}=0$. The current value and the first lag of $y_{i, t}^{\star}$ are included in the specification of each country's VAR to capture international comovements in the cycle. We adopt the same procedure to model exchange rates. We include, among the country-specific variables, the real exchange relative to the U.S. dollar, $s_{i, t}$, and the following global variable

$$
s_{i, t}^{\star}=\sum_{j=1}^{n-1} w_{i j} s_{j, t} \quad i \neq j
$$

\section{Results}

The presentation of our results is organized in four subsections. We start by discussing the robustness of fiscal multipliers estimated on panels of countries. We then explain why it is important to keep track of debt dynamics and we show this with a case study of the U.S. We close the section by showing our empirical results.

\subsection{On the robustness of international fiscal multipliers}

We start our empirical analysis by replicating the available international evidence on the fiscal transmission mechanism (e.g. Alesina Ardagna 2010, IMF 2010), which, as we said, is typically based on the panel estimation of a cross-country output equation. The specification, which is very similar to the one presented in equation (4), is a regression of the growth rate of real GDP on a set of current and lagged values of fiscal shocks and lagged GDP growth. In particular, IMF (2010) estimates, on their sample of fifteen OECD countries the following equation:

$$
\Delta y_{i, t}=\alpha+A_{1}(L, 1) \Delta y_{i, t-1}+B(L, 2) \varepsilon_{i, t}^{g}+C(L, 2) \varepsilon_{i, t}^{\tau}+\lambda_{i}+\nu_{t}+\mu_{i, t}
$$

The equation includes a full set of country dummies, $\lambda_{i}$, to account for differences in trend growth rates across countries and time dummies, $\nu_{t}$, to account for global shocks, such as shifts in oil prices or the global business cycle. 
We replicate the results of the IMF study by reporting in Figure 4a-4b the multiplier with respect to an aggregate fiscal shock, $\varepsilon_{i, t}^{g}+\varepsilon_{i, t}^{\tau}$, obtained by imposing $B(L, 2)=C(L, 2)$. When aggregate shocks are considered, the estimated multiplier is statistically significant but smaller than 1 .

\section{[Insert Figure 4A-4B Here]}

The simple empirical model described by (12) imposes very strong restrictions. The effects of fiscal consolidations are assumed to be identical across countries: the only heterogeneity allowed for is that captured by the fixed effects in the panel estimation. We doubt that this global fiscal multiplier is a useful concept for the selection of the structural model to be used for policy advice. The following assumptions, in particular, appear to be very restrictive:

- fiscal shocks are assumed to be homogeneous across all countries. No heterogeneity in the fiscal policy mix is allowed for;

- the responses of output to fiscal shocks are computed overlooking their effects on the dynamics of the debt. The specification thus rules out the possibility that fiscal dynamics differ across countries characterized by different debt levels. It also shuts down another possibly important effect, namely the effect that fiscal shocks can exert on interest rates;

- fiscal multipliers are assumed to be the same in small and open, and large and less open economies. Moreover, the effect of a global fiscal shock is assumed to be the same as that of a local fiscal shock for each of the countries included in the sample.

\subsection{On the importance of tracking debt dynamics}

To illustrate the importance of keeping track of the debt dynamics we start by considering a restricted version of our general empirical model. Equation (13) encompasses the single equation specification used in the IMF study. But it also allows to keep track of the debt dynamics when computing impulse responses, thus checking whether multipliers are computed along divergent fiscal paths. Otherwise it replicates the IMF study in that no debt feedback is imposed. (Note that because we now keep track of debt dynamics the sample is restricted to only eight countries, those for which the debt dynamics could be reconstructed from the set of identities in (9))

$$
X_{i, t}=C_{i, 1}+C_{i, 2} X_{i, t-1}+\gamma_{i}^{g} \varepsilon_{i, t}^{g}+\gamma_{i}^{\tau} \varepsilon_{i, t}^{\tau}+\mu_{i, t}
$$

with $X_{i, t}=\left[y_{i, t}, g_{i, t}, \tau_{i, t}, \tau_{i, t}, p_{i, t}\right]$. The usual set of identities in (9) is appended to (13) in order to track debt dynamics endogenously. The model for $X_{i, t}$ can be interpreted as a set of stacked closed economy VARs: no exchange rate is included and no common 
fluctuations among different components of $X_{i, t}$ across countries is allowed for. Moreover, if panel restrictions are imposed, such that, for every country $i, C_{i, 1}=C_{1}, C_{i, 2}=C_{2}$, $\gamma_{i}^{g}=\gamma^{g}$ and $\gamma_{i}^{\tau}=\gamma^{\tau}$, (13) can be re-interpreted as an approximation of the truncated MA representation of (12).

We have estimated the system (13) on data from our sample of eight countries. Figure $4 \mathrm{~b}$ shows that the estimated multipliers replicate very closely those obtained with the IMF specification, equation (12) and reported in Figure 4a.

Figure 5 reports the simulated debt dynamics for each of the countries in the sample and it clearly shows that for some of the countries the common multiplier is computed along an unstable debt path.

\section{[Insert Figure 5 Here]}

We now come to the core of the paper. We shall estimate fiscal multipliers in a model that allows for debt stabilization, international comovements and cross country heterogeneity. Before attacking this problem, however, we show a case study of the U.S. to document the error one can make by omitting the debt-deficit dynamics.

\subsection{The effects of overlooking the debt feedback: a case study of the U.S.}

This section illustrates the importance of keeping track of the effects of fiscal policy on the debt when estimating fiscal multipliers. We study what we have assumed to be a closed economy, the U.S. We choose to do so because, as already mentioned, the analysis of fiscal policy shocks on the U.S., modelled as a closed economy, has so far been the benchmark in the literature. We start by estimating two models for the U.S. economy on the sample 1980-2009: a standard VAR model without debt feedback (13) and one with debt feedback. (In this case the set of regressors in each of the VAR equations is augmented by the lagged debt-to-gdp ratio and the debt dynamics is modeled by the identities in (9).

In practice, we consider the following system of equations for the US economy

$$
X_{\mathrm{us}, t}=C_{\mathrm{us}, 0}+C_{\mathrm{us}, 1} t+C_{i, 2} X_{\mathrm{us}, t-1}+\varphi_{\mathrm{us}} D_{\mathrm{us}, t-1}+\gamma_{\mathrm{us}}^{g} \varepsilon_{\mathrm{us}, t}^{g}+\gamma_{\mathrm{us}}^{\tau} \varepsilon_{\mathrm{us}, t}^{\tau}+\mu_{\mathrm{us}, t}
$$

where, as above, $X_{\mathrm{us}, t} \equiv\left[y_{\mathrm{us}, t}, g_{\mathrm{us}, t}, \tau_{\mathrm{us}, t}, i_{\mathrm{us}, t}, p_{\mathrm{us}, t}\right]$. The vector of coefficients $\boldsymbol{\varphi}_{\text {us }}$ describes the feedback from the lagged debt-GDP ratio to the variables included in the system. As in the previous Sections, the debt dynamics is endogenized by appending to the system in (14) the identities described in (9).

To understand the importance of allowing for a debt feedback in estimating the fiscal multiplier, we shall consider two alternative specifications of this model. First, we analyze the fiscal VAR in (14) without feedback, that is, we impose the restriction $\varphi_{\mathrm{us}}=0$. Next, we relax this assumption and re-estimate the same model allowing for $\varphi_{\mathrm{us}} \neq 0$. When we 
do this we let $\varphi_{\mathrm{us}}=\left\{0, \varphi_{\mathrm{us}}^{g}, \varphi_{\mathrm{us}}^{\tau}, \varphi_{\mathrm{us}}^{i}, \varphi_{\mathrm{us}}^{p}\right\}$, that is we let the feedback affect all variables $X_{\mathrm{us}, t}$ except $y_{\mathrm{us}, t}$. We shall refer to this model as the fiscal VAR with debt feedback.

The two alternative specifications, with and without debt feedback, have strikingly different effects on the dynamics of the endogenous variables following a fiscal shock - and this plays an important role when computing fiscal multipliers. To illustrate this point, we report in Figure 6 the simulated out-of sample dynamics of output growth, of the debt-to-GDP ratio, the primary deficit-to-GDP ratio, and the cost of financing the debt, as generated by the VAR without feedback (left column) and with a debt feedback (right column). The simulated series are generated by taking, as initial conditions for all variables, their value in 2009 and then projecting each future path up to 2020 by solving the model forward.

\section{[INSERT Figure 6 HeRe]}

Figure 6 shows that the dynamics implied by the VAR model with no debt feedback is unstable for all fiscal variables, although real GDP growth converges to a long-run value of about four per cent. The same long-run steady state for growth is obtained by the model with debt-feedback, but with a very different path for the fiscal variables.

The out-of-sample simulation of the model without feedback produces a path for all the endogenous variables that does not guarantee debt stabilization. Along this path: (i) the debt-to-GDP ratio reaches 1.75 in 2020, (ii) an unsustainable fiscal policy cumulates yearly primary deficits in the range of 10-20 percent of GDP, (iii) the rapid increase in the debt ratio has no effect on interest rates - in effect, following the historical trend, the cost of debt service falls to zero, (iv) despite the divergence of the debt ratio, real growth converges rapidly toward its steady state value estimated at 2 percent. The results from the model with a debt feedback are very different. In the fiscal VAR with feedback debt stabilization is achieved because the initial fiscal expansion, occurred in 2008-2009, is eventually reversed, and the dynamics of the cost of financing switches form an increasing path to a converging one. The projected dynamics of the model with feedback reveals all the features of a sustainable debt dynamics: (i) the debt-to-GDP ratio converges quickly towards its steady state value, (ii) the primary deficit after its peak at 10 per cent of GDP in 2009 is progressively reduced and turns into a surplus by 2014-2020, (iii) interest rates respond positively to the fiscal expansion, but also to the inversion in the path of the deficit, and eventually converge progressively toward a level between 2 and 3 per cent, (iv) output growth converges to its steady state level of 2 per cent .

This evidence shows that impulses responses computed on the two models should be interpreted very differently. In the case of the model without feedback the initial shock lands the economy on an unsustainable fiscal path, while in the case of the model with feedback this does not happen.

To further elaborate on this point, for each of the two different specifications of model 
(14), we simulated the effect of a fiscal shock corresponding to $1 \%$ of GDP, respecting the historical policy style, i.e. the correlation between tax and spending shocks that characterizes the US experience. In Figure 7 we show the responses of output and of the primary deficit.

\section{[Insert Figure 7 Here]}

The results are interesting. Consider first the response of output to the fiscal adjustment under the two models, with and without the debt feedback: there is no difference between the two specifications. A clear difference, instead, emerges when we compare the effect of the fiscal adjustment on the primary deficit. In the model without feedback, the fiscal contraction has a permanent effect on the primary deficit. The deficit falls and then remains permanently negative. This explains what we observe in Figure 6 where the debt-to-GDP ratio lands on a diverging path. Instead, in the model with feedback, the effect of the initial shock on the primary deficit is eventually reversed, and the debt ratio converges towards its long run mean.

The lesson from Figure 7 is that fiscal multipliers cannot be inferred by simply analyzing the impulse response of output to a fiscal shock because the same impulse response can correspond to very different fiscal multipliers. In our case, in the model without feedback, an initial fiscal retrenchment of $1 \%$ of GDP determines, after 5 years, a total fiscal retrenchment of $11 \%$ of GDP. In the model with feedback the total fiscal retrenchment generated by the same initial shock is instead $8 \%$ of GDP. The same total effect an outputnamely a marginally significant expansion of about $2 \%$ over a 5 -year period- is therefore obtained with a change in the deficit/GDP ratio which differs by 3 per cent between the two simulated fiscal manoeuvres.

\subsection{Computing the effects of fiscal policy allowing for heterogeneity}

We now come to the central point of our paper. We estimate fiscal multipliers in a model that allows for debt stabilization, international comovements and cross country heterogeneity. We do this using the full model presented in (2) to compute the effects of a fiscal contraction of $1 \%$ of GDP obtained with a mix of tax increase and expenditure reduction that reflects, country by country, the historical pattern of fiscal policy. The model allows for different policy styles across countries, different debt-deficit dynamics and different degrees of exposure to the international cycle. Table 1 illustrates the significance of the debt feedback by reporting the estimated coefficients on the debt in the fiscal reaction function of the different countries. Note that debt stabilization plays a role in all countries: as the difference between the feedback coefficients implies a positive feedback of the primary surplus to the debt to GDP ratio, with the only exception of Japan. The style of stabilization is however heterogenous across countries: lagged debt impacts more significantly (with a negative sign) on expenditures in Canada and the US while it has instead 
a more significant (positive) coefficients on taxes in the cases of Italy, France and the UK.

\section{[Insert Figure 8 and Table 1 Here]}

The output multipliers for the eight countries, reported in Figure 8, document a very high level of heterogeneity, suggesting that an aggregate homogeneous fiscal multiplier, such as the one reported in Figure 4, would be difficult to interpret. The output response to a fiscal retrenchment ranges from significantly contractionary in Belgium and France, to not significantly different from zero in the U.K., Sweden,and Italy, to initially zero and then slightly espansionary in Canada, and the U.S., to significantly expansionary in Japan.

Interestingly, the country that shows a significant non-Keynesian effect of a fiscal policy retrenchment on output is Japan, which in our sample is the country that has shown the most unstable debt dynamics with no mean reversion in the debt to GDP ratio.

\section{Robustness}

In this section we check the robustness of our findings of heterogeneity in fiscal multipliers to two modifications of the fiscal shocks included in our model. We first analyze the impact of local rather than international fiscal shocks, then we address explicitly the potential endogeneity of narrative fiscal shocks.

\subsection{Country-specific versus global shocks}

So far the type of fiscal policy experiment considered is a simultaneous fiscal consolidation across all countries in our sample. In fact, this is the type of shocks that is effectively analyzed in the IMF studies when computing the fiscal multiplier based on the pooled output growth equation and reported in Figure 4a. In the non-linear GVAR specification there is no need for imposing the restriction that fiscal policy is synchronized across all countries as the extended specification of the model allows for heterogeneity across countries and for experimenting with local policy shocks. We have implemented such an experiment by running eight different simulations, one for each country in the sample, in which only one country at time is subject to a fiscal shock while the others are inactive. We collected the impulse responses in Figure 9

\section{[INSERT Figure 9 Here]}

The results strengthen our general point on the importance of allowing for heterogeneity. Consider for example the case of the similarity of the output response to fiscal policy in Canada and the USA that we reported in Figure 8 while analyzing the effect of a global fiscal shocks. Such similarity totally disappears in Figure 9 where we consider the response to a local shock. In fact, the US response is virtually unaltered while the 
response in Canada is practically flat at zero. This evidence shows that the exercise based on a synchronized shock was basically measuring the response of the Canadian economy to a US policy shocks rather than the fiscal multiplier in Canada. In other words, while in the US a fiscal consolidation is expansionary (in the medium run), the same shift in fiscal policy has no effect on output in Canada. However when the US cuts spending and raise taxes, output raises not only in the US but also in Canada. The same does not happen symmetrically for the US when Canada consolidates, most likely because of the different size of the two economies. The identification of the two separate effects requires the higher degree of heterogeneity of the non-linear GVAR model. In general, although all responses to local shocks are smaller than those based on global shocks, Canada is the only case in which there is a dramatic difference between these two experiments.

\subsection{Are the Devries et al. (2011) narrative shocks exogenous?}

Our second robustness check is based on a closer analysis of the exogeneity of the narrative shocks. Our specification strategy, based on the direct inclusion of the narrative shocks in the non-linear VAR model, takes for granted the exogeneity of the tax hikes and the expenditure cuts considered by Devries et al.(2011). Narrative shocks are based on the exam of intentions and actions as described in policy documents to identify measures motivated primarily by deficit reductions. Such fiscal actions represent a response to past decisions and past economic conditions rather than to prospective conditions. As it is clearly stated by Devries et al.(2011) "they are unlikely to be systematically correlated with other developments affecting output in the short-term and are thus valid for estimating the macroeconomic effects of fiscal consolidations", however it is possible that these narrative shocks capture the systematic response of fiscal policy to the debt dynamics rather than its surprise components. The analysis of the impact of shocks to the policy reaction functions implicitly estimated in a VAR is not based on changing any estimated parameters and it is not therefore subject to the Lucas' critique (see Lucas(1976) despite the nature of a reduced form model of any VAR. This argument cannot be applied to the narrative identified shocks inserted in a VAR if they are not orthogonal to the relevant information set. In fact, if the orthogonality property is not satisfied a modification in the narrative shocks might effectively involve a change in the parameters of the reduced form model. To fix ideas consider this simplified version of a fiscal reaction functions which decomposes the dynamics of a generic fiscal policy variable into an automatic output stabilization component, $\left(\beta_{1} y_{t}\right)$, a discretionary output stabilization component, $\left(\beta_{2} y_{t-1}\right)$ a discretionary debt stabilization component, $\left(\beta_{3} d_{t-1}\right)$, and a fiscal shock, $u_{t}^{f p}$ :

$$
f p_{t}=\beta_{0}+\beta_{1} y_{t}+\beta_{2} y_{t-1}+\beta_{3} d_{t-1}+u_{t}^{f p}
$$

The narrative approach is constructed to filter out of the fiscal variable the automatic and discretionary output component but change in fiscal policy motivated by deficit reductions may reflect the true fiscal shock $u_{t}^{f p}$ as well as the discretionary fiscal debt 
stabilization component. In other words the narrative approach might lead to identify as fiscal shocks $\left(f p_{t}-\beta_{0}-\beta_{1} y_{t}-\beta_{2} y_{t-1}\right)$ rather than $u_{t}^{f p}$, generating a potential endogeneity bias in the GVAR specification augmented with debt dynamics. To address this potential problem, we have evaluated fiscal shocks against the information set of our GVAR by first regressing the narrative shocks on lags of output only and then by regressing them on the full information set used in our non-linear GVAR. The results reported in Table 2 show that indeed the shocks are orthogonal to lags of output but that they are not always orthogonal to the full information set included in the non-linear GVAR model. To evaluate the consequences of this fact we have re-run our model by keeping the original narrative shocks for the countries where they are orthogonal to the full information set, and by substituting to the original narrative shocks the residuals of the regression of the narrative shocks on the relevant information set for the countries where the orthogonality hypothesis has been clearly rejected. The results, reported in Figure 10 that is directly comparable with Figure 9 as we consider the output responses to local shocks, show that the heterogeneity evidence is robust to the orthogonalization of the shocks, although for some of the countries, the shape of the impulse responses is somewhat affected (even if the impact effect is not).

\section{[Insert Figure 10 and Table 2 Here]}

\section{Conclusions}

The main conclusion of our empirical analysis is that the question "what is the fiscal policy multiplier" asked unconditionally is impossible to answer empirically and makes little sense theoretically. There is no unconditional fiscal policy multiplier. The effect of fiscal policy on output is different according to the different debt dynamics, the different degree of openness and the different fiscal reaction functions in different countries. Pooling together the evidence for different countries to derive a single measure of the effect of fiscal retrenchments on output is therefore is of very little use to describe the effect of exogenous shifts in fiscal policy on output. In this paper we have derived empirical evidence on fiscal multipliers by specifying a global non-linear VAR that allows for the three sources of heterogeneity mentioned above. Moreover, our model generates fiscal multipliers computed along paths that are not inconsistent with a positive value of government bonds. We find results that sharpen our understanding of the effects of fiscal policy. In particular: (i) international spillovers are important. In the case of Canada, for instance, it makes a big difference whether a fiscal consolidations happens contemporaneously also in the U.S., or only in Canada; (ii) the initial level of debt and the stability of the debt ratio seem to determine whether a shift in fiscal policy has "keynesian" or "non-keynesian" effects. In our group of countries we find evidence of non-keynesian effects only in Japan. This is the only country in our sample where fiscal policy does not respond to the level of debt and where the debt level is non mean-reverting. 
The empirical results on the heterogeneity in the effect of fiscal policy in our paper should not be used to answer policy questions such as "How should a government respond to a particular macro shock?". These questions need to be addressed within the framework of quantitative general equilibrium models of the business cycle - i.e. within the context of a theoretical macro model rather than on an empirical reduced form econometric model. Empirical results like those presented in this paper should be however considered in the specification of a DSGE model relevant for policy simulation analysis. 


\section{References}

[1] Alesina A. and Ardagna S. [2010]: "Large changes in Fiscal Policy: Taxes versus Spending", Tax Policy and the Economy, vol.24, edited by J.R.Brown.

[2] Auerbach A., Y. Gorodnichenko [2011]: "Measuring the Output Response to Fiscal Policy", American Economic Journal: Economic Policy.

[3] Bachmann R., E.R. Sims [2011]: "Confidence and the Transmission of Government Spending Shocks", NBER Working Paper 17063.

[4] Bohn, Henning [1998]: "The Behaviour of U.S. public debt and deficits", Quarterly Journal of Economics, 113, 949-963.

[5] Cloyne, J. [2011]: "What are the Macroeconomic Effects of Tax Changes in the United Kingdom", mimeo, University College London.

[6] Corsetti G., Meier A. and G. Mueller [2009]: "Fiscal Stimulus with Spending Reversals", CEPR DP 7302.

[7] Dees, S., di Mauro, F., Pesaran, M. H. \& Smith, L. V. [2007]: "Exploring the international linkages of the euro area: a global VAR analysis", Journal of Applied Econometrics, 22(1), 1-38.

[8] Devries, Pete, Jaime Guajardo, Daniel Leigh, and Andrea Pescatori [2011]: "A New Action-based Dataset of Fiscal Consolidation," IMF Working Paper No. 11/128. The dataset is available on the IMF's website (http://www.imf.org/external/pubs/cat/longres.aspx?sk=24892.0).

[9] Favero, C. and F. Giavazzi [2007]: "Debt and the effects of fiscal policy", NBER Working paper no. 12822, April.

[10] Ghosh A., J.I. Kim, E.G. Mendoza, J.Ostry, M.Qureshi [2011]: "Fiscal fatigue, fiscal space and debt sustainability in advanced economies", NBER working paper 16782.

[11] Ilzetzki E. [2011]: "Fiscal Policy and Debt Dynamics in Developing Countries", mimeo, London School of Economics.

[12] Ilzetzki E. and C.Vegh [2011] "How Big (Small) are Fiscal Multipliers?", paper presented at the IMF-EUI Conference on Fiscal Policy, Stabilization and Sustainability, Florence June 6-7 2011.

[13] IMF [2010]: "Will it hurt? Macroeconomic Effects of Fiscal Consolidation", World Economic Outlook, Chapter 3, October. 
[14] Hansen, L. P., and Sargent T. J. [1991]: "Two Difficulties in Interpreting Vector Autoregressions", in Rational Expectations Econometrics, ed. by L. P. Hansen, and T. J. Sargent, pp. 77-119. Westview Press, Boulder, CO.

[15] Kilian, Lutz \& Vigfusson, Robert J., [2011]: "Nonlinearities in the Oil Price-Output Relationship," CEPR Discussion Papers 8174, C.E.P.R.

[16] Leeper E. M., Walker T., and Yang S.C. [2008]: "Fiscal Foresight: analytics and Econometrics", mimeo.

[17] Leeper E. M. [2010]: "Monetary Science, Fiscal Alchemy", Federal Reserve Bank of Kansas City's Jackson Hole Symposium, Macroeconomic Policy: Post-Crisis and Risks Ahead, August 26-28, 2010.

[18] Lucas R.J.[1976]: "Econometric Policy Evaluation. A Critique", in Brunner K. and A. Meltzer, the Phillips Curve and the Labour Markets, Carnegie-Rochester Conference Conference Series on Public Policy.

[19] Killian L. and R.Vigfusson [2010]: "Are the Responses of the US Economy Asymmetric in energy Prices Increases and Decreases ?" paper available at http://wwwpersonal.umich.edu/ lkilian/kv032310.pdf.

[20] Mertens K. and Ravn M. O. [2011]: "Measuring Fiscal Shocks in Structural VARs using Narrative Data", mimeo.

[21] Perotti, R. [2011]: "Expectations and Fiscal Policy. An Empirical Investigation", mimeo, IGIER, Bocconi University, paper available at www.igier.unibocconi.it/perotti.

[22] Pesaran, M. H., Schuermann, T. and Weiner, S. M. [2004a]: "Modelling Regional Interdependencies using a Global Error-Correcting macro-econometric model", Journal of Business and Economic Statistics 22(2), 129-162.

[23] Romer, Christina and Romer, David H. [2010]: "The Macroeconomic Effects of Tax Changes: Estimates Based on a New Measure of Fiscal Shocks", American Economic Review, 100, 763-801.

[24] Zubairy S.[2011] "On Fiscal Multipliers: Estimates from a medium scale DSGE model", Banque of Canada Working Papaer 2010-30 
Belgium

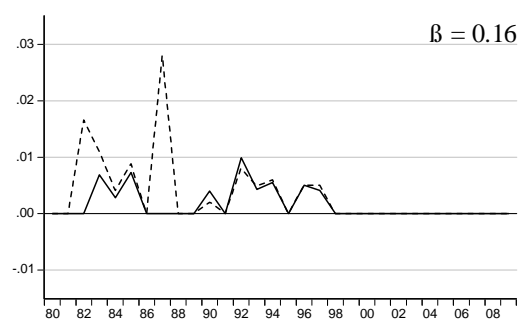

France

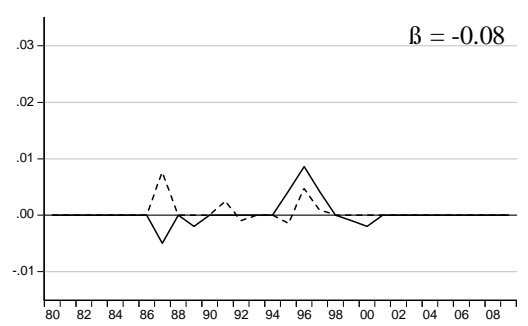

Japan

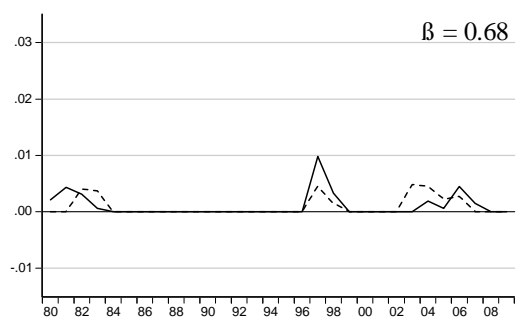

United Kingdom

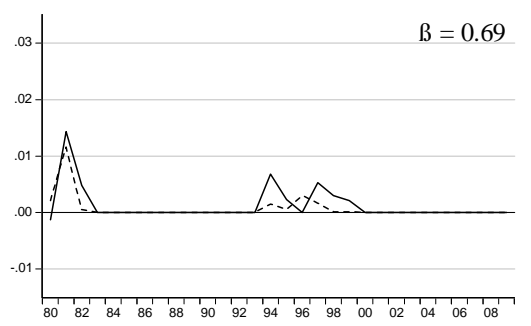

Canada

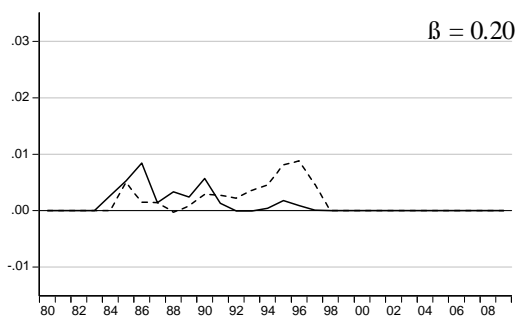

Italy

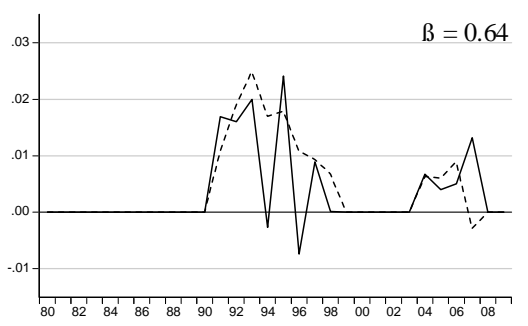

Sweden

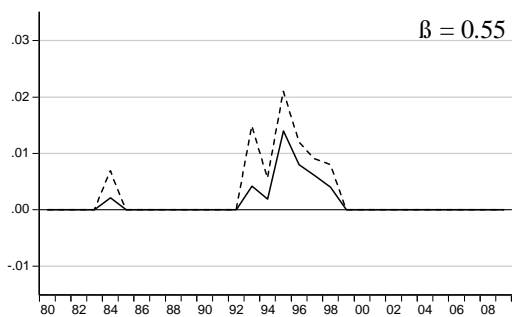

United States

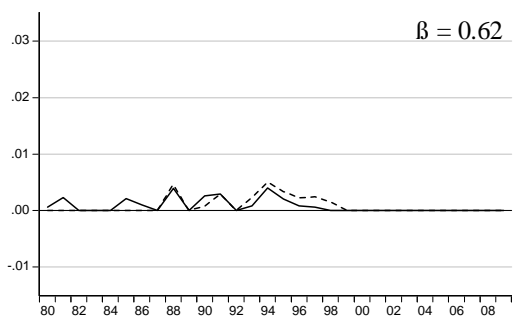

-.-- Spending Cuts — Tax Hikes

Figure 1: The style of fiscal consolidations 


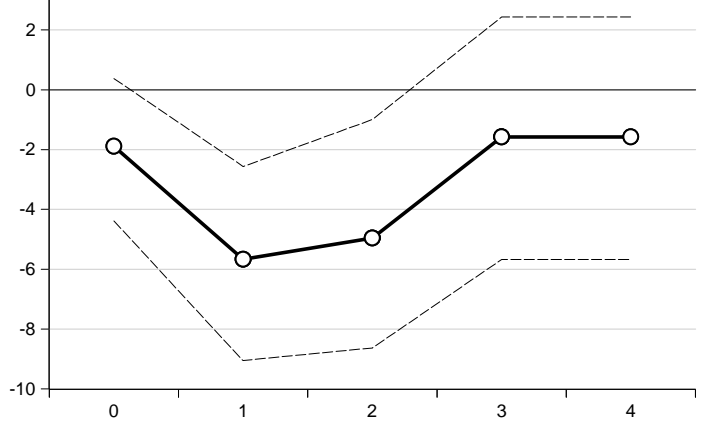

(b): Tax Hikes only

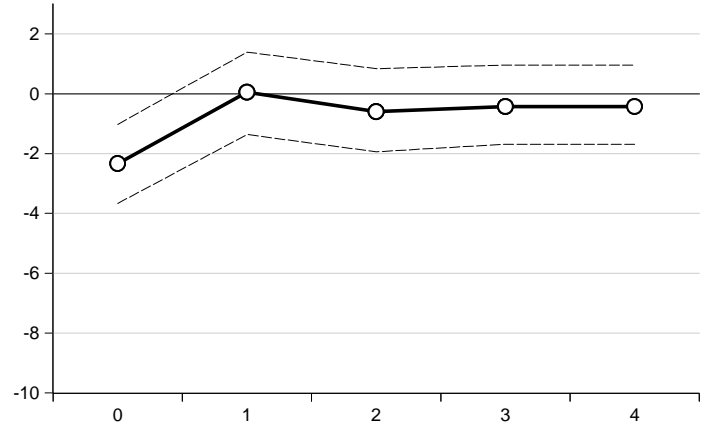

(b): Tax Hikes and Spending Cuts, Balanced Shock Figure 2: Impulse Responses of Output to different fiscal shocks. USA only. 
Belgium

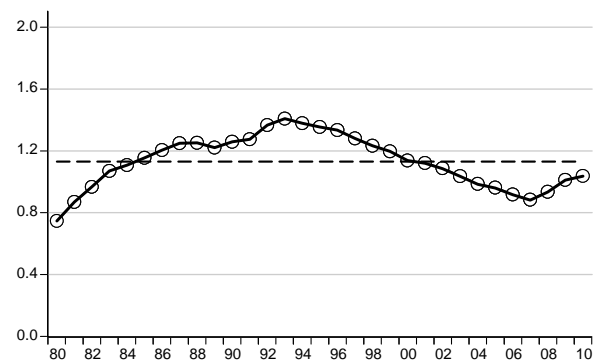

France

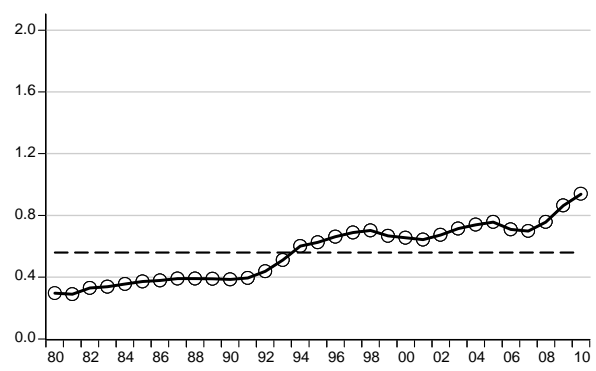

Japan

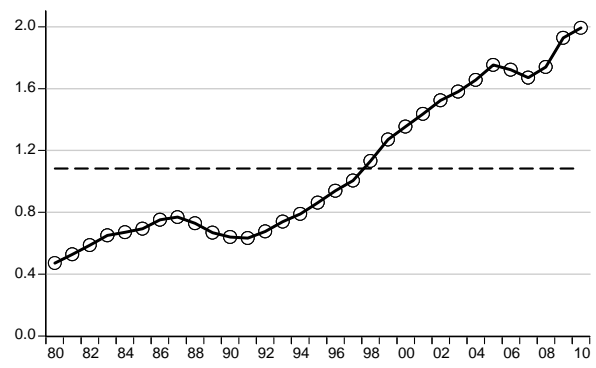

Sweden

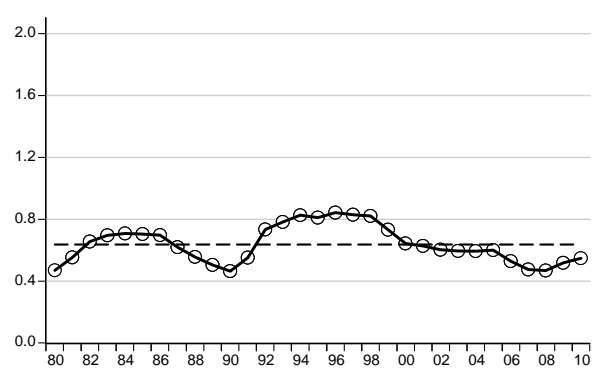

Canada

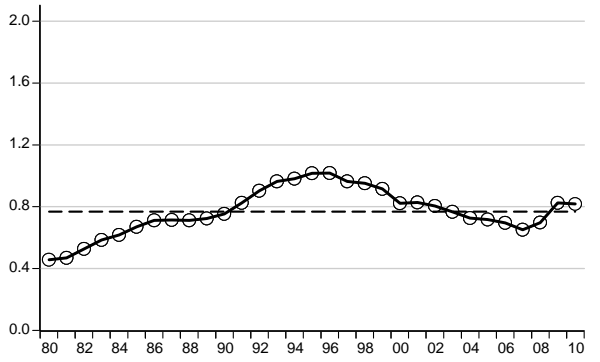

Italy

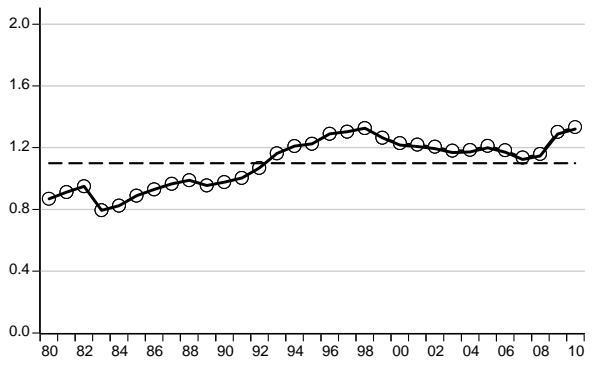

United Kingdom

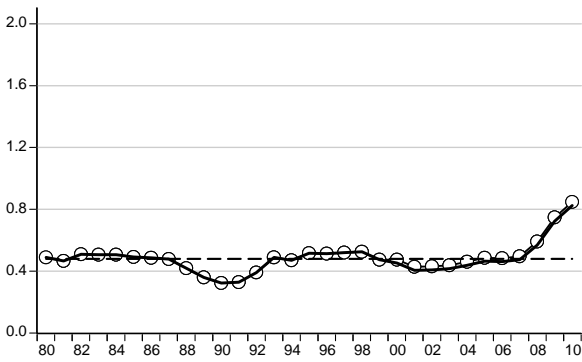

United States

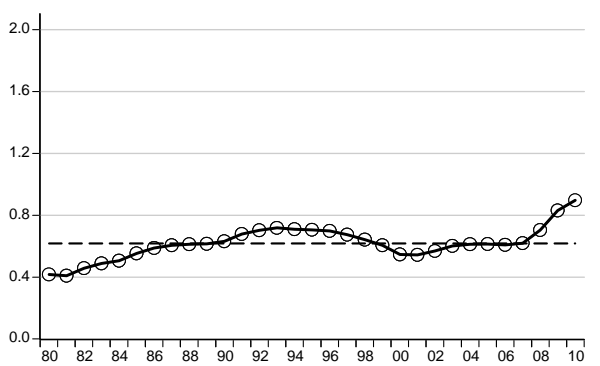

$\multimap$ - Tracked Debt — Actual Debt - -- Sample Mean

Figure 3: Tracking Debt Dynamics 


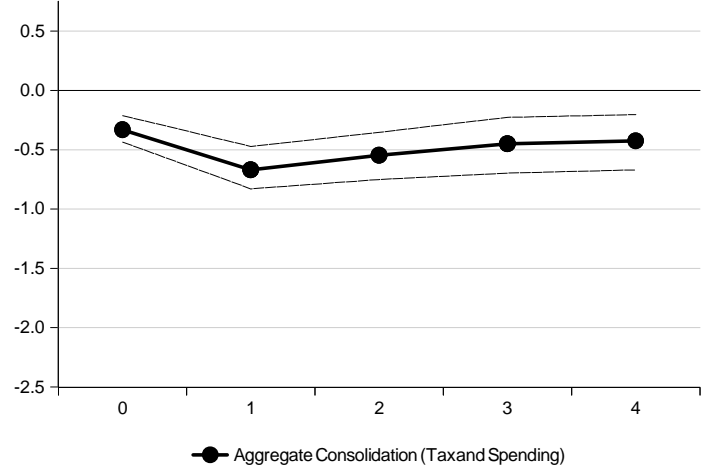

Figure 4a: IMF Replication, single equation, 15 OECD countries

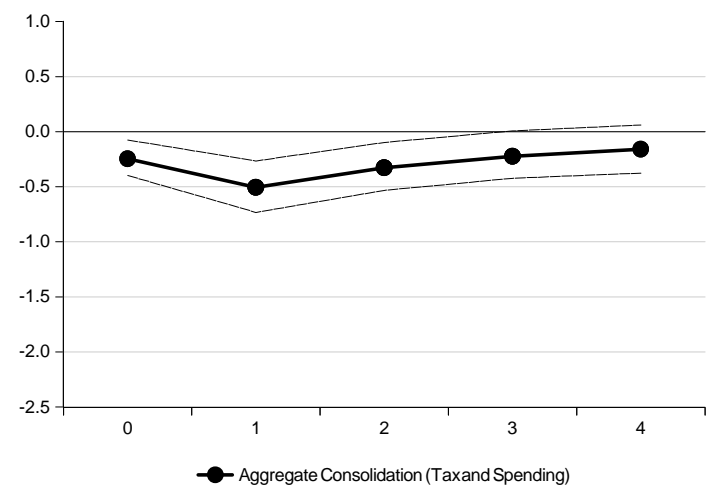

Figure 4b: Restricted VAR, no debt feedback 8 OECD countries 
Belgium

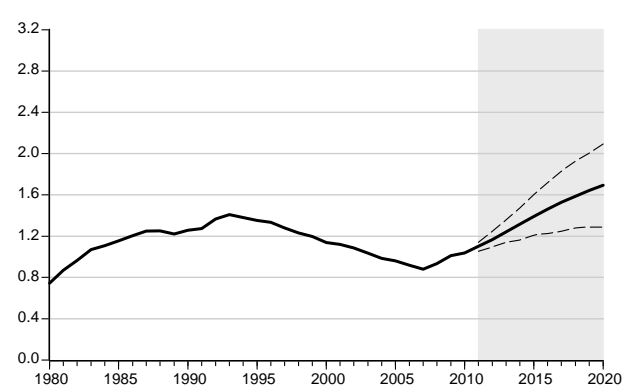

France

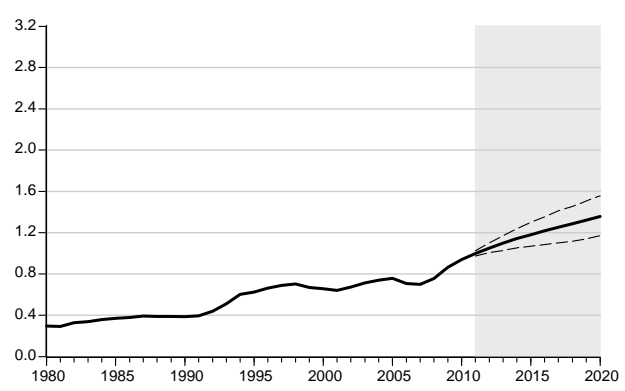

Japan

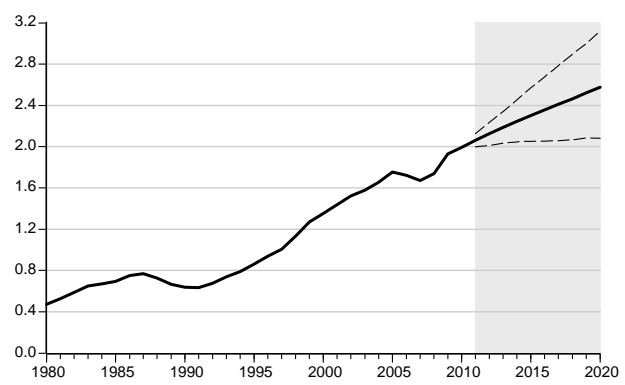

United Kingdom

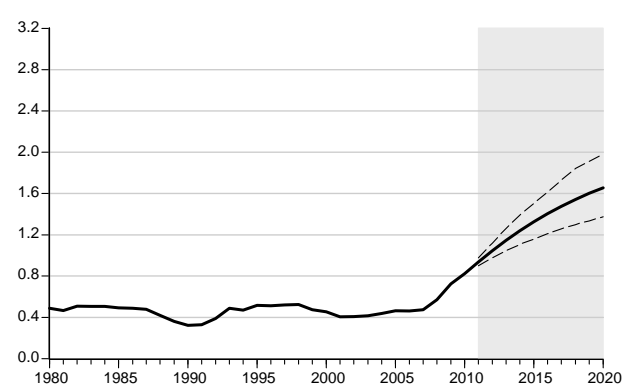

Canada

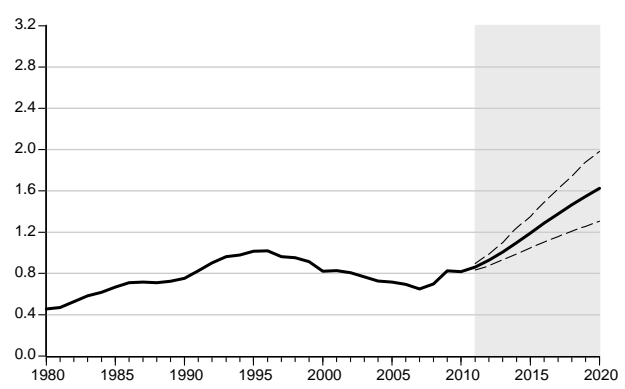

Italy

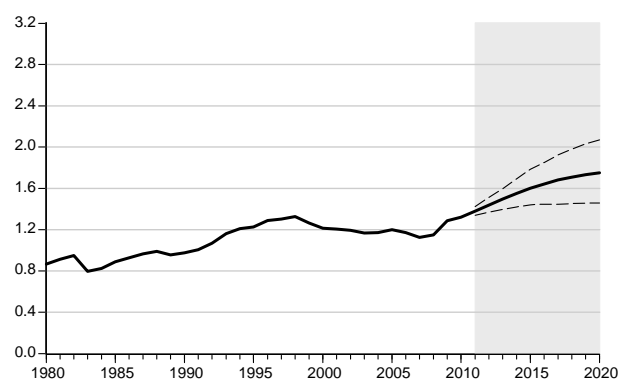

Sweden

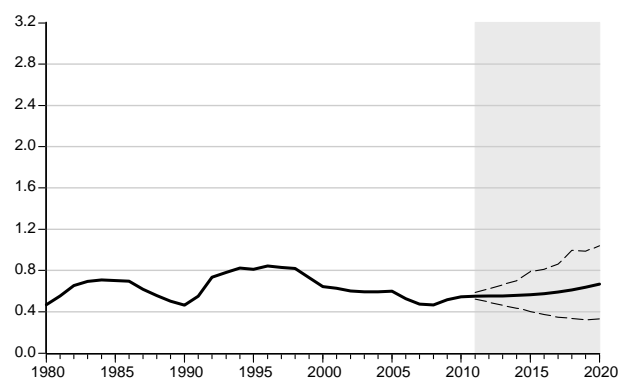

United States

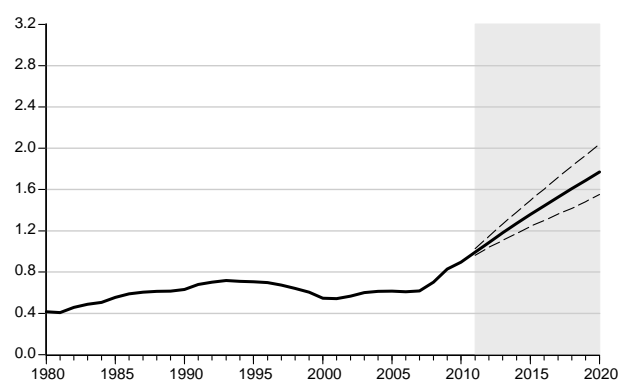

Figure 5: Debt dynamics out-of-sample simulations (shaded area). 
(a) Without Debt Feedback

Debt

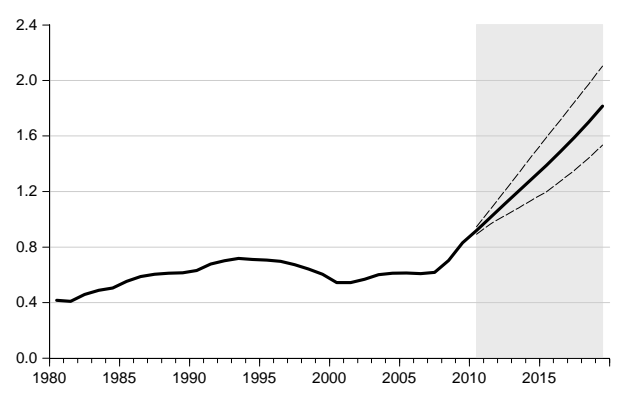

Real Output Growth

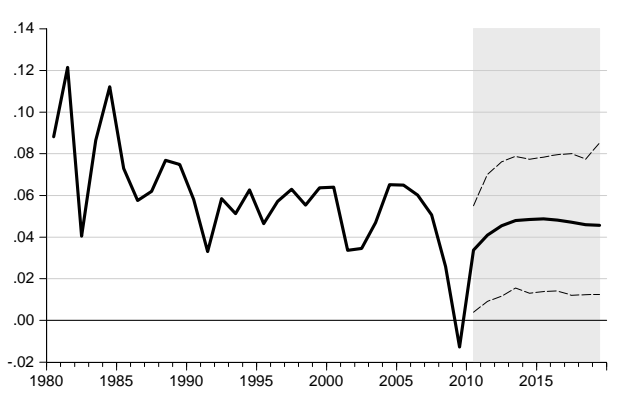

Primary Deficit

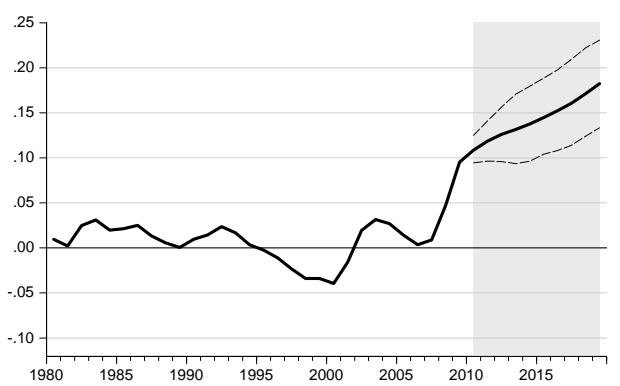

Cost of Financing the Debt

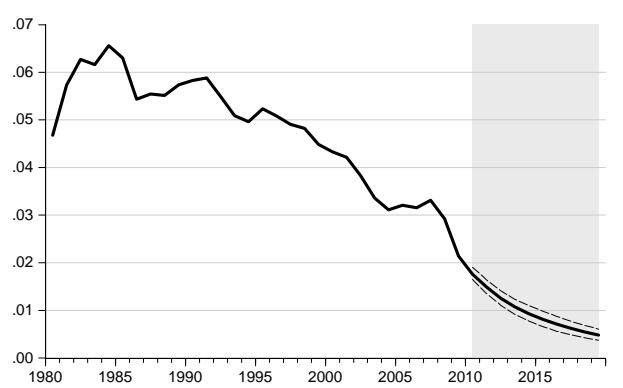

(b) With Debt Feedback

Debt

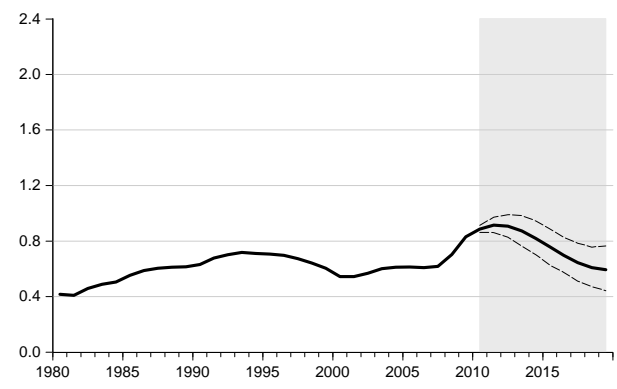

Real Output Growth

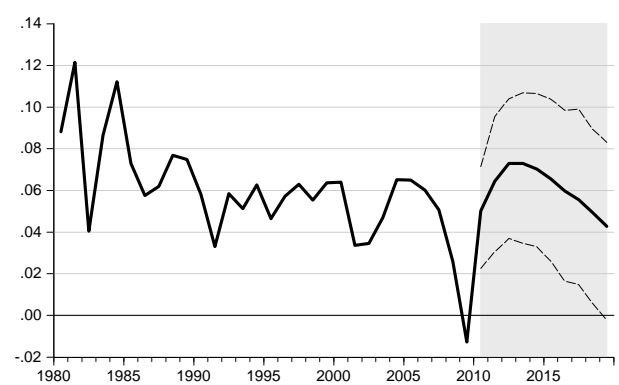

Primary Deficit

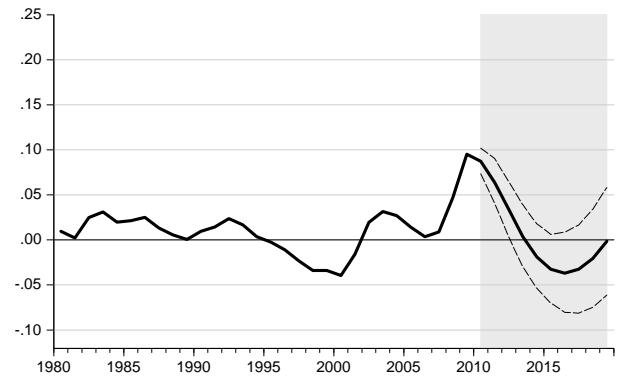

Cost of Financing the Debt

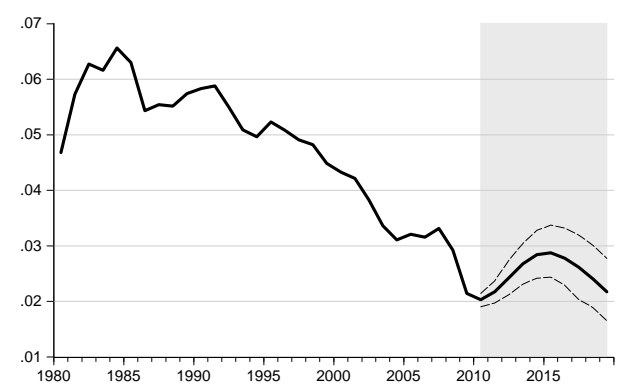

Figure 6: USA, Simulated paths of macro variables with and without a debt feedback. 
(a): Without Debt Feedback

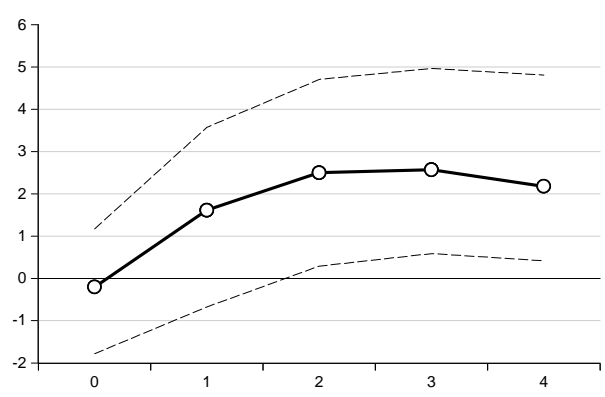

Output

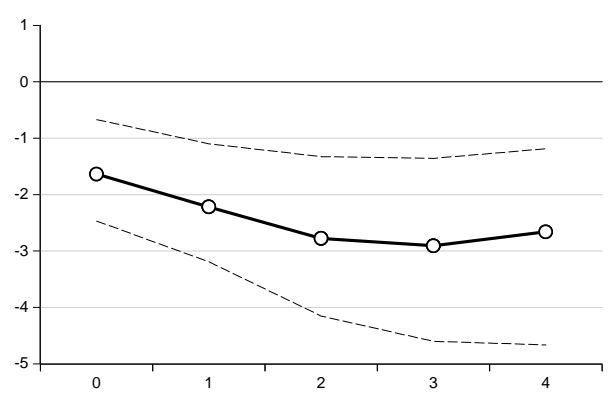

Primary Deficit (b): With Debt Feedback

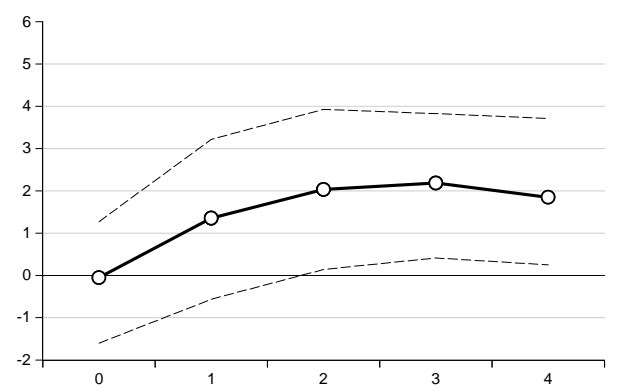

Output

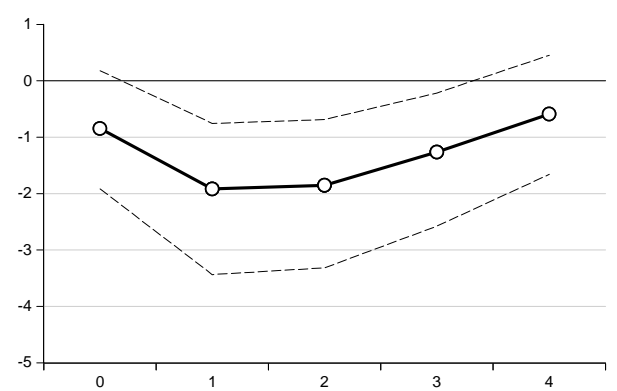

Primary Deficit

Figure 7: Impulse Responses to aggregate fiscal consolidation shocks, USA only. 
Belgium

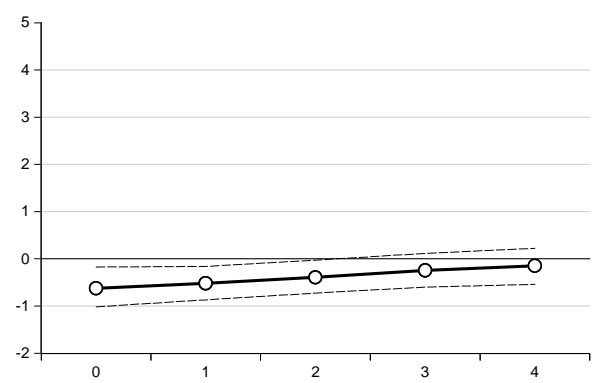

United Kingdom

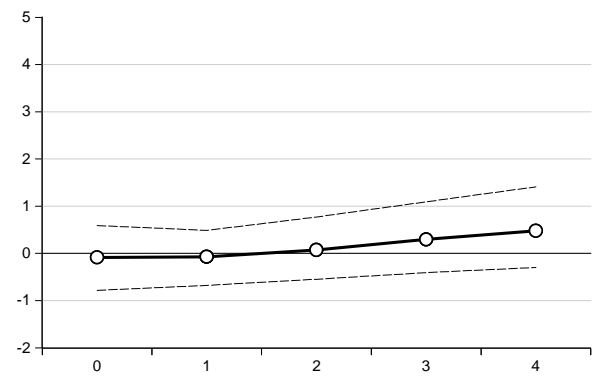

Canada

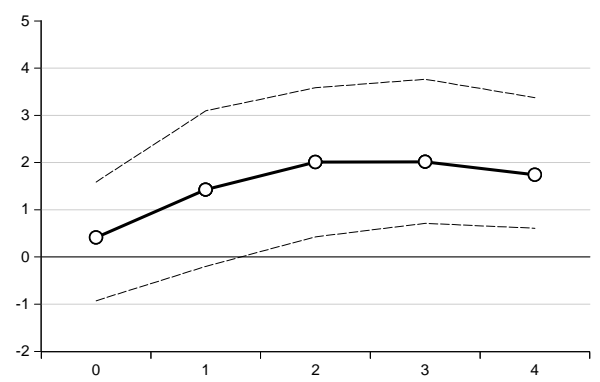

Japan

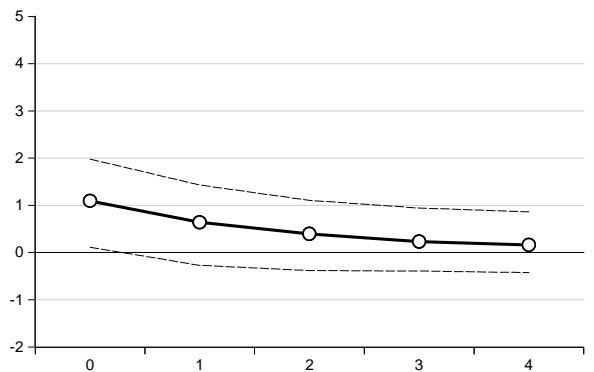

France

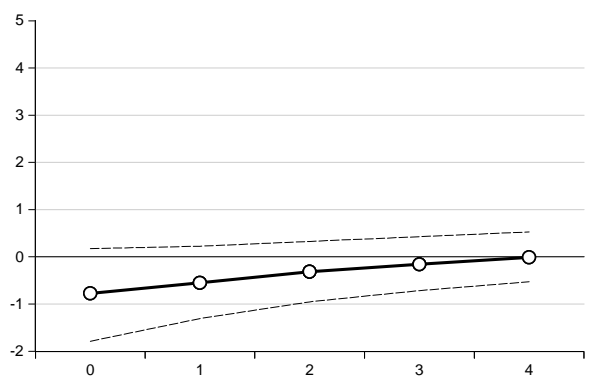

Italy

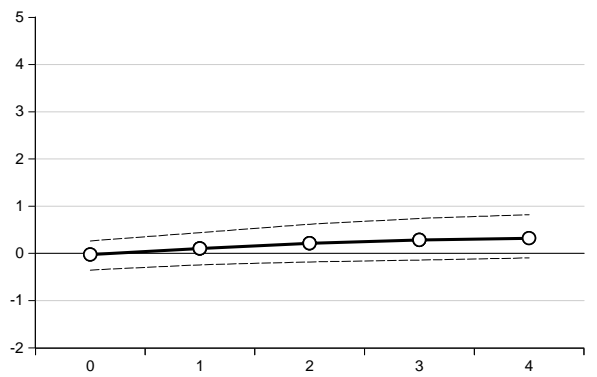

United States

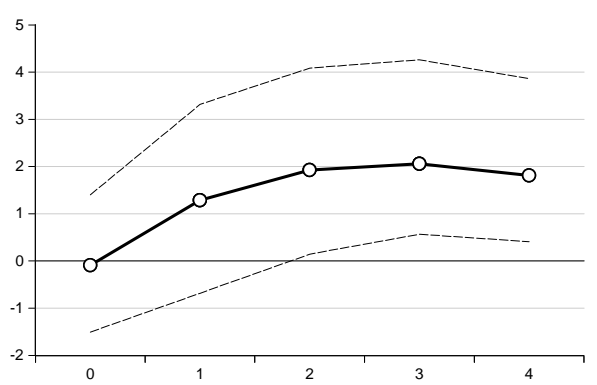

Sweden

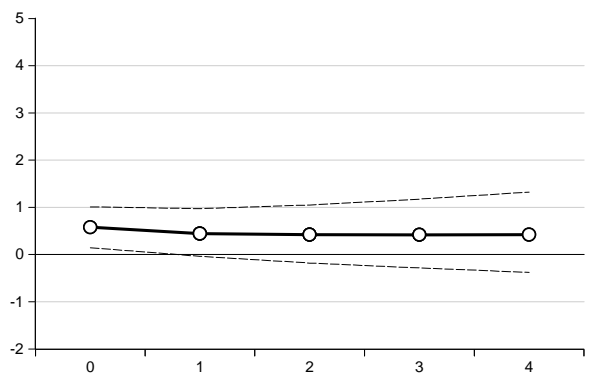

Figure 8: Output Responses to global fiscal consolidation shocks. 
Belgium

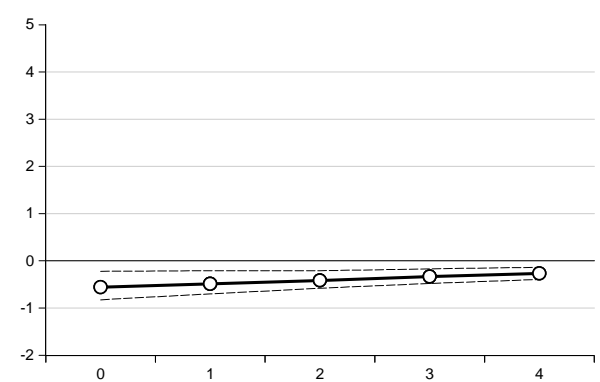

United Kingdom

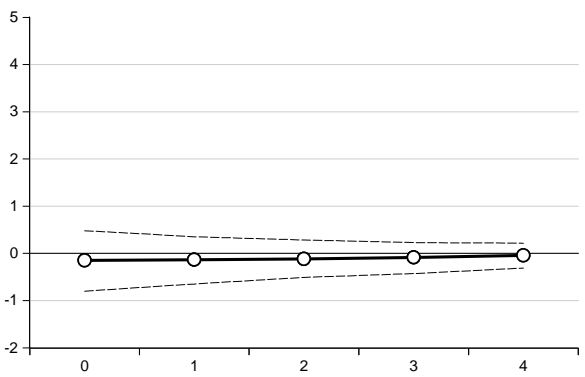

Canada

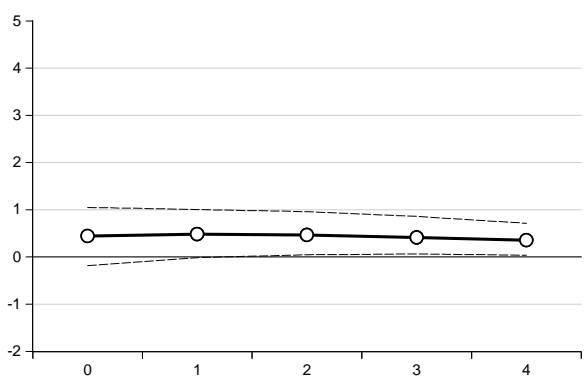

Japan

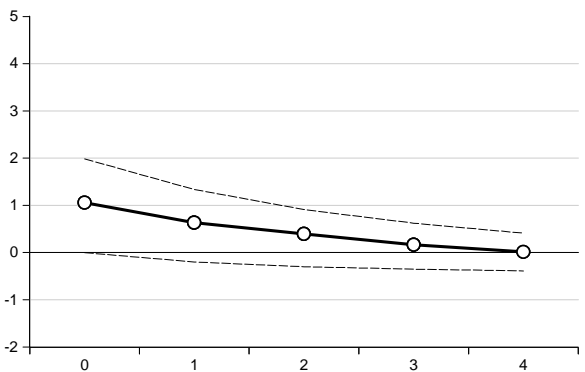

France

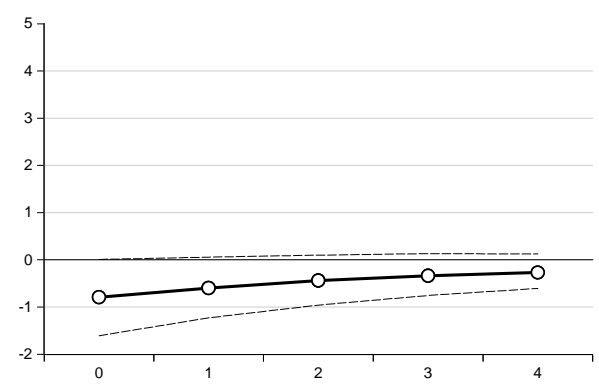

Italy

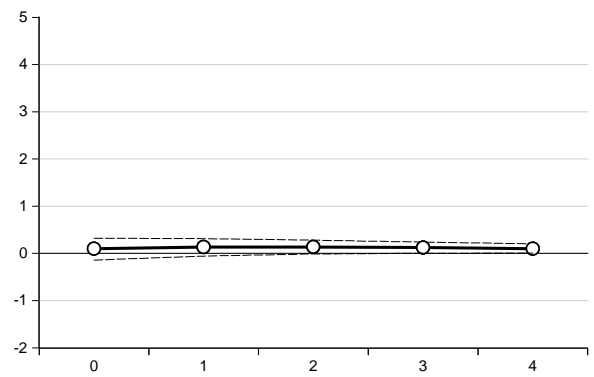

United States

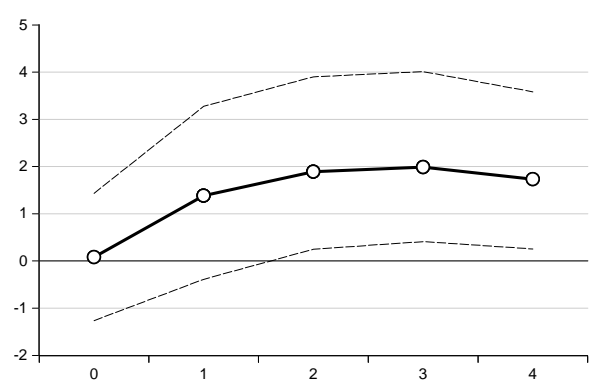

Sweden

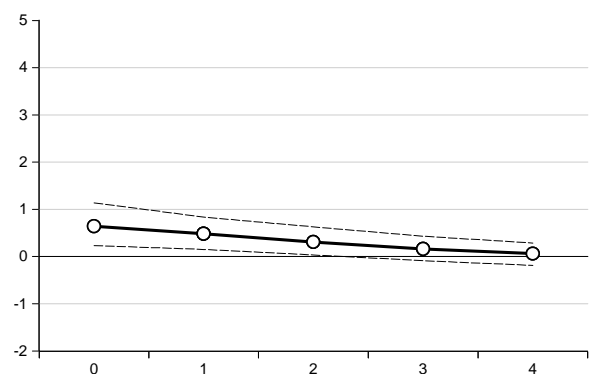

Figure 9: Output responses to local fiscal consolidation.shocks 
Belgium

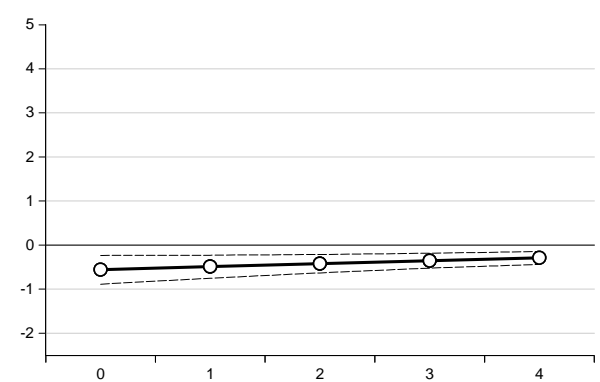

United Kingdom

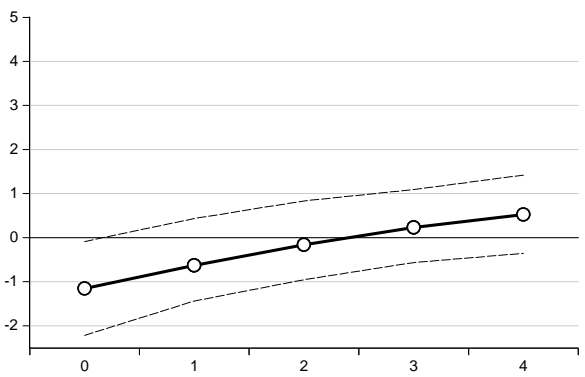

Canada

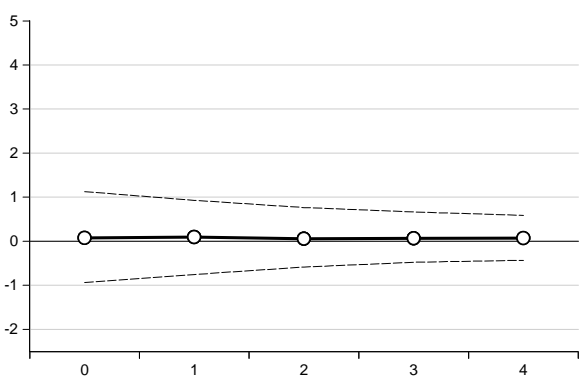

Japan

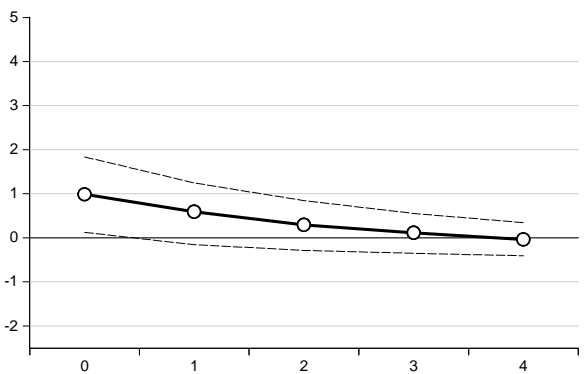

France

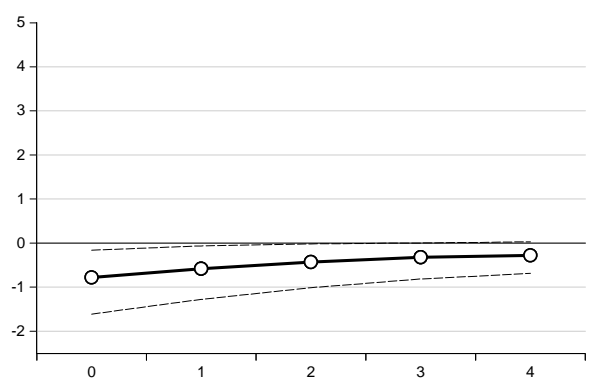

Italy

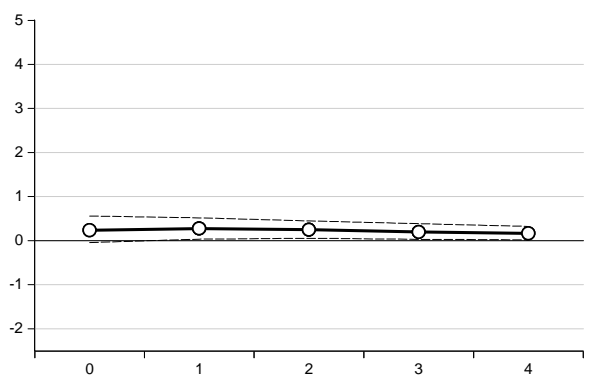

United States

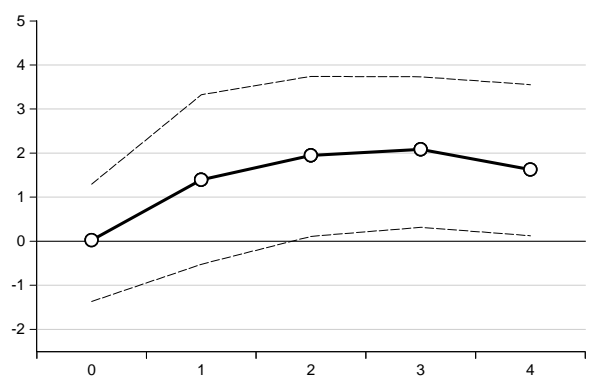

Sweden

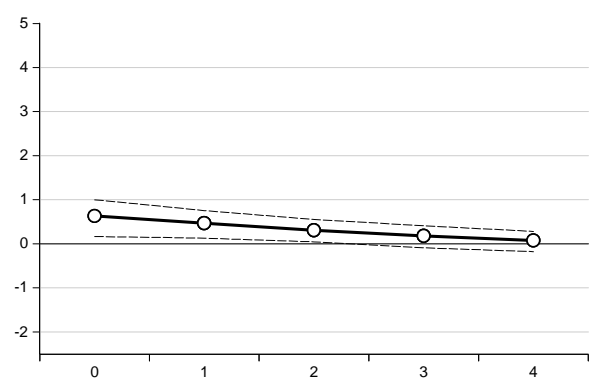

Figure 10: Output responses to local fiscal consolidation shocks orthogonalized to $\mathcal{I}_{t-1}$ 


\begin{tabular}{|c|c|c|}
\hline Countries & $\begin{array}{c}\text { Expenditures } \\
\qquad g_{t}\end{array}$ & $\begin{array}{c}\text { Revenues } \\
\tau_{t}\end{array}$ \\
\hline Belgium & $\begin{array}{l}-0.038 \\
(-0.27)\end{array}$ & $\begin{array}{l}0.030 \\
(0.35)\end{array}$ \\
\hline Canada & $\begin{array}{l}-0.149 \\
(-2.25)\end{array}$ & $\begin{array}{l}-0.072 \\
(0.27)\end{array}$ \\
\hline France & $\begin{array}{l}0.036 \\
(0.57)\end{array}$ & $\begin{array}{l}0.144 \\
(1.56)\end{array}$ \\
\hline Italy & $\begin{array}{l}-0.110 \\
(-2.12)\end{array}$ & $\begin{array}{l}0.218 \\
(3.18)\end{array}$ \\
\hline Japan & $\begin{array}{l}0.015 \\
(0.10)\end{array}$ & $\begin{array}{l}0.180 \\
(1.52)\end{array}$ \\
\hline Sweden & $\begin{array}{c}-0.072581 \\
(-0.64)\end{array}$ & $\begin{array}{c}0.045513 \\
(0.38)\end{array}$ \\
\hline United Kingdom & $\begin{array}{l}0.183 \\
(2.02)\end{array}$ & $\begin{array}{l}0.086 \\
(0.47)\end{array}$ \\
\hline United States & $\begin{array}{l}-0.292 \\
(-2.23)\end{array}$ & $\begin{array}{c}0.47 \\
(1.62)\end{array}$ \\
\hline
\end{tabular}

Table 1: Coefficients of $b_{t-1}$ (t-Stats in parenthesis) 
Exogeneity of spending shocks $\varepsilon_{i, t}^{g}$

$$
\begin{aligned}
& \mathcal{I}_{i, t}=\left\{y_{i, t-1}, y_{i, t-2}\right\} \\
& \begin{array}{c|c|c|c|c|c|c|c|c}
F \text {-Stat } & 4.41 & 0.15 & 0.14 & 1.71 & 0.24 & 0.12 & 4.17 & 0.04 \\
F \text {-Prob } & 0.021 & 0.85 & 0.86 & 0.19 & 0.78 & 0.88 & 0.025 & 0.95 \\
\mathcal{I}_{i, t}=\left\{X_{i, t-1}, X_{i, t-2}, b_{i, t-1}, b_{i, t-2}, y_{i, t}^{*}, y_{i, t-1}^{*}, s_{i, t}^{*}, s_{i, t-1}^{*}\right\} \\
F \text {-Stat } & 0.98 & 4.03 & 1.22 & 5.48 & 1.00 & 3.14 & 4.93 & 2.29 \\
F \text {-Prob } & 0.51 & 0.015 & 0.35 & 0.001 & 0.49 & 0.029 & 0.006 & 0.06
\end{array}
\end{aligned}
$$

Exogeneity of tax shocks $\varepsilon_{i, t}^{\tau}$

$$
\begin{aligned}
& \mathcal{I}_{i, t}=\left\{y_{i, t-1}, y_{i, t-2}\right\} \\
& \begin{array}{l|c|c|c|c|c|c|c|c}
F \text {-Stat } & 1.78 & 3.54 & 0.11 & 0.70 & 0.01 & 0.23 & 4.10 & 1.68 \\
F \text {-Prob } & 0.18 & 0.04 & 0.89 & 0.50 & 0.98 & 0.79 & 0.026 & 0.20 \\
\mathcal{I}_{i, t}=\left\{X_{i, t-1}, X_{i, t-2}, b_{i, t-1}, b_{i, t-2}, y_{i, t}^{*}, y_{i, t-1}^{*}, s_{i, t}^{*}, s_{i, t-1}^{*}\right\} \\
F \text {-Stat } & 2.77 & 10.4 & 1.94 & 1.30 & 0.67 & 3.40 & 4.34 & 1.17 \\
F \text {-Prob } & 0.03 & 0.0003 & 0.11 & 0.31 & 0.77 & 0.022 & 0.004 & 0.38
\end{array}
\end{aligned}
$$

